\title{
Optimizing Operation of Water Supply Reservoir: The Role of Constraints
}

\author{
Tongtiegang Zhao and Jianshi Zhao \\ State Key Laboratory of Hydro-Science and Engineering, Department of Hydraulic Engineering, Tsinghua University, \\ Beijing 100084, China \\ Correspondence should be addressed to Jianshi Zhao; zhaojianshi@tsinghua.edu.cn
}

Received 22 October 2013; Revised 18 December 2013; Accepted 18 December 2013; Published 18 March 2014

Academic Editor: Yi-Kuei Lin

Copyright (c) 2014 T. Zhao and J. Zhao. This is an open access article distributed under the Creative Commons Attribution License, which permits unrestricted use, distribution, and reproduction in any medium, provided the original work is properly cited.

\begin{abstract}
This paper presents a mathematical analysis of water supply reservoir operation. The analysis illustrates one-stage, two-stage, and three-stage formulations of multiple-period reservoir operation depending on the effects of operational constraints. There is a onestage model when storage capacity constraints are nonbinding. Release decisions depend on total water availability and exhibit equal marginal utilities. Binding upper (lower) storage capacity constraint blocks the effect of decreased (increased) water availability in the subsequent stages on release decisions in the preceding stages. When one storage capacity constraint is binding, multiple periods become two stages and a gap occurs between marginal utilities of water. When there are one upper and one lower binding storage capacity constraints, reservoir operation is characterized as a three-stage model. Effects of forecast uncertainty and ending storage on reservoir operation are affected by reservoir storage capacity. When the storage capacity constraints are nonbinding, the reservoir can regulate streamflow in an extended timeframe, and current release decision is affected by forecast uncertainty of total streamflow and ending storage. When the storage capacity constraints are binding, the reservoir can regulate streamflow only in a short timeframe, and current release decision is primarily affected by forecast uncertainty of streamflow in the current stage.
\end{abstract}

\section{Introduction}

Optimization models have been widely used in reservoir operation to determine optimal decisions [1-3]. These models characterize reservoir systems with decision variables, objective function, and constraints and use numerical algorithms to determine operation decisions. Linear programming, dynamic programming, and nonlinear programming are optimization models commonly used in reservoir operation [4-6]. Linear programming is used for solving problems involving linear objective functions and constraints. Dynamic programming treats multiple-period reservoir operation as recursive two-stage optimization to obtain optimal solutions. Nonlinear programming provides a general formulation of reservoir operation but requires complicated algorithms to be solved. Unlike empirical operating rules, optimization models effectively exploit streamflow forecasts and improve reservoir system efficiency [7-9].
Reservoir operation is a sequential process [10-12]. Operation decisions in preceding periods affect water availability (WA) in subsequent periods, and future streamflow conditions affect current decision-making. Streamflow forecast provides useful information on streamflow, and the proper use of such forecast considerably improves reservoir operation [13-15]. Taking forecasts as inputs, optimization models output optimal operation decisions. In this process, optimization models act as black boxes that do not interpret relationships between input and output. Geoffrion [16] stated that optimization provides not only results but also insights. Many studies have developed optimization models for reservoir operation $[3,17,18]$. The current study attempts to conduct mathematical analysis of optimization models and to illustrate the relationship between input forecast and output decision.

Mathematical analysis provides insights on the optimization of reservoir operations, particularly those related to 
water supply problems. Trade-offs exist between current and future water usages because water is a scarce resource. Hedging rules, which reduce water delivery to cope with water shortage risks caused by uncertainty of future streamflow, have been widely discussed in the literature and used in practice $[19,20]$. Based on the framework of two-stage optimization, Draper and Lund [21] interpreted the rationale behind hedging, which holds that the expected marginal benefit of storage, that is, future water delivery, must be equal to the marginal benefit of current release. Following the marginal value principle, You and Cai [22] incorporated forecast uncertainty in the analysis of hedging. Shiau [23] derived analytical hedging by considering balances between beneficial release and carried-over storage value. Zhao et al. [24] elaborated the constraints of hedging and illustrated the effects of water balance, nonnegative release, and storage capacity constraints on hedging decisions. Mathematical analysis addresses the rationale behind hedging and facilitates the many applications of hedging in reservoir operation practices [25-27].

Mathematical analysis of reservoir operation is usually limited to conceptual two-stage models [21-23]. In this study, we extend the analysis of constraints in the twostage model [28] and present a general analysis of multipleperiod reservoir operation, which is more practical for real-world cases. One important finding is that reservoir operation can be formulated as one-stage, two-stage, and three-stage models depending on the effects of constraints. The different formulations result from binding upper (lower) storage capacity constraint that blocks the effect of decreased (increased) water availability in subsequent stages on release decisions in preceding stages. When the storage capacity constraints are nonbinding, the reservoir can regulate streamflow in an extended timeframe, and current release decision is affected by the forecast uncertainty of total streamflow and ending storage. When the storage capacity constraints are binding, the reservoir can regulate streamflow only in a short timeframe, and current release decision is primarily affected by the forecast uncertainty of streamflow in stage 1 . The analysis highlights the importance of storage capacity in reservoir operation.

The rest of this paper is organized as follows. Section 2 formulates a general optimization model for multiple-period reservoir operation. Section 3 discusses the functions of water balance, release capacity, and storage capacity constraints. Section 4 presents an extended analysis of the effects of forecast uncertainty and ending storage and Section 5 provides the conclusions.

\section{Problem Formulation}

Reservoir operation of water supply balances the release of multiple periods to maximize total utility. Release in one period yields economic utility and affects WA and utilities in other periods. This section formulates the optimization model for water supply reservoir operation and illustrates the optimality conditions of operation decisions.
2.1. Multiple-Period Water Supply Optimization. Consider a reservoir problem with a study horizon of $H$ periods. We use $t$ as the index of time periods. In reservoir operation, the variables are as follows:

$$
\begin{aligned}
& s_{t}: \text { reservoir storage at the beginning of period } t \text { (the } \\
& \text { end of period } t-1) ; \\
& r_{t}: \text { release in period } t .
\end{aligned}
$$

The parameters are as follows:

$$
\begin{aligned}
& \bar{s}_{t}: \text { the upper bound of } s_{t} ; \\
& \underline{s}_{t}: \text { the lower bound of } s_{t} ; \\
& \bar{r}_{t}: \text { the upper bound of } r_{t} \text {, that } \\
& \text { demand in period } t ; \\
& \underline{r}_{t}: \text { the lower bound of } r_{t} \text {, th } \\
& \text { requirement in period } t ; \\
& q_{t}: \text { streamflow in period } t \text {; } \\
& s_{\text {ini }}: \text { the initial storage; } \\
& s_{\text {end }}: \text { the ending storage. }
\end{aligned}
$$$$
\bar{r}_{t} \text { : the upper bound of } r_{t} \text {, that is, the maximum water }
$$$$
\underline{r}_{t} \text { : the lower bound of } r_{t} \text {, that is, the minimum water }
$$

Based on the aforementioned variables and parameters, we select $r_{t}$ as the decision variable and formulate an optimization model of $H$ periods of reservoir operation with the following streamflow sequence $\left[q_{1}, q_{2}, \ldots, q_{H}\right]$ :

$$
\begin{array}{cl}
\max _{\left[r_{1}, r_{2}, \ldots, r_{H}\right]} & B=\sum_{t=1}^{H} b_{t}\left(r_{t}\right) \\
\text { s.t. } & s_{t}+q_{t}-r_{t}=s_{t+1} \quad(t=1,2, \ldots, H) \\
& \underline{r}_{t} \leq r_{t} \leq \bar{r}_{t} \quad(t=1,2, \ldots, H) \\
& \underline{s}_{t} \leq s_{t} \leq \bar{s}_{t} \quad(t=2,3, \ldots, H) \\
& s_{1}=s_{\text {ini }} \\
& s_{H+1}=s_{\text {end }} .
\end{array}
$$

In (1), the objective function is to maximize the total utility $B$ (the sum of single-period utilities from period 1 to $H$ ). An important characteristic of single-period utility function $b_{t}\left(r_{t}\right)$ is concavity, which denotes that the utility gain from an increase in $r_{t}$ diminishes as $r_{t}$ increases (i.e., diminishing marginal utility) $[21,22,29]$. The three typical constraints of water balance, release capacity, and storage capacity are incorporated into (1) [3]. Initial and ending storage constraints are also integrated into the equation. To avoid unnecessary complexity for the analysis, (1) does not explicitly consider the spill that occurs under excessive WA. Spill is discussed in Section 3.2. Evaporation and leakage are also considered to be negligible in (1).

Reservoir storage, which is refilled by streamflow and drawn down by release, carries over water between periods and functions as a link in multiple-period reservoir operation (Figure 1). On the basis of the water balance relationship, $s_{t+1}$ can be reformulated as the sum of initial storage and 


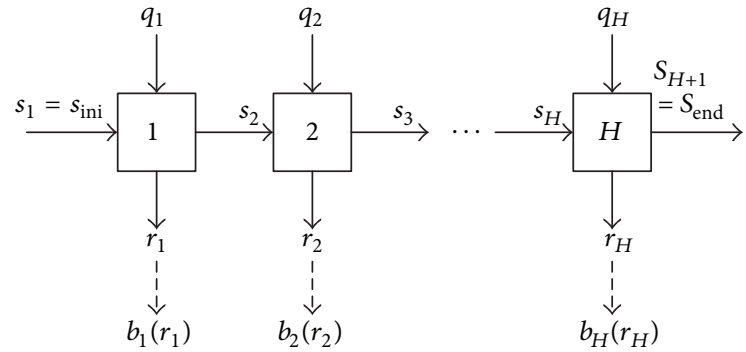

FIGURE 1: Schematic of formulation of multiple-period water supply reservoir operation (Solid line indicates the water balance relationship; dashed line represents economic utility).

the difference between streamflow and release from periods 1 to $t[10,12]$ as follows:

$$
\begin{aligned}
s_{t+1} & =s_{t}+q_{t}-r_{t} \\
& =s_{t-1}+q_{t-1}-r_{t-1}+q_{t}-r_{t} \\
& =\cdots \\
& =s_{\text {ini }}+\sum_{i=1}^{t} q_{i}-\sum_{i=1}^{t} r_{i} .
\end{aligned}
$$

By using (2), we can express the storage capacity constraint of $s_{t+1}$ as follows:

$$
\begin{gathered}
s_{\text {ini }}+\sum_{i=1}^{t} q_{i}-\sum_{i=1}^{t} r_{i} \leq \bar{s}_{t+1}, \\
s_{\text {ini }}+\sum_{i=1}^{t} q_{i}-\sum_{i=1}^{t} r_{i} \geq \underline{s}_{t+1} .
\end{gathered}
$$

Moreover, incorporating the ending storage into (2) yields total WA, which is equal to the total release:

$$
\sum_{t=1}^{H} r_{t}=\sum_{t=1}^{H} q_{t}+\left(s_{\text {ini }}-s_{\text {end }}\right) \text {. }
$$

Based on (2) to (4), we reformulate (1) into the standard form of nonlinear optimization as follows:

$$
\begin{array}{cl}
\underset{\left[r_{1}, r_{2}, \ldots, r_{H}\right]}{\max } & B=\sum_{t=1}^{H} b_{t}\left(r_{t}\right) \\
\text { s.t. } & \sum_{i=1}^{H} r_{i}=\sum_{i=1}^{H} q_{i}+\left(s_{\text {ini }}-s_{\text {end }}\right) \\
& r_{t} \leq \bar{r}_{t} \quad(t=1,2, \ldots, H) \\
- & r_{t} \leq-\underline{r}_{t} \quad(t=1,2, \ldots, H) \\
& s_{\text {ini }}+\sum_{i=1}^{t} q_{i}-\sum_{i=1}^{t} r_{i} \leq \bar{s}_{t+1} \\
& (t=1,2, \ldots, H-1)
\end{array}
$$

$$
\begin{array}{r}
-s_{\text {ini }}-\sum_{i=1}^{t} q_{i}+\sum_{i=1}^{t} r_{i} \leq-\underline{s}_{t+1} \\
(t=1,2, \ldots, H-1) .
\end{array}
$$

Reservoir operation for water supply is a resource allocation problem. The scarce resource of water availability WA $=$ $\sum_{i=1}^{H} q_{i}+\left(s_{\text {ini }}-s_{\text {end }}\right)$ is allocated among $\left[r_{1}, r_{2}, \ldots, r_{H}\right]$ to maximize the total utility. Aside from scarce WA, reservoir operation is also subject to limited regulating capacity: (1) the upper bound $\bar{r}_{t}$ of release; (2) the lower bound $\underline{r}_{t}$ of release; (3) the upper bound $\bar{s}_{t+1}$ of storage, which sets the maximum of storage refill from periods 1 to $t$; $(4)$ the lower bound $\underline{s}_{t+1}$ of storage, which sets the maximum of storage drawn down from periods 1 to $t$ (decrease in $\underline{s}_{t+1}$ indicates increase in $-\underline{s}_{t+1}$, allowing for the drawing down of more storage).

2.2. Optimality Conditions and Economic Interpretations. The optimization model of water supply in ((5), (6), (7), (8), (9), and (10)) represents a convex optimization problem with a concave objective function and linear constraints. Consider the following general nonlinear optimization problem:

$$
\begin{array}{cl}
\max _{\left[x_{1}, x_{2}, \ldots, x_{K}\right]} & B\left(x_{1}, x_{2}, \ldots, x_{K}\right) \\
\text { s.t. } & h_{1}\left(x_{1}, x_{2}, \ldots, x_{K}\right)=0 \\
& \vdots \\
& h_{M}\left(x_{1}, x_{2}, \ldots, x_{K}\right)=0 \\
& g_{1}\left(x_{1}, x_{2}, \ldots, x_{K}\right) \leq 0 \\
& \vdots \\
& g_{N}\left(x_{1}, x_{2}, \ldots, x_{K}\right) \leq 0 .
\end{array}
$$

This model maximizes the total profit $B\left(x_{1}, x_{2}, \ldots, x_{K}\right)$ from $K$ types of products, which are denoted by decision variables $\left[x_{1}, x_{2}, \ldots, x_{K}\right]$, subject to constraints of resource availability. The scarce resources in optimization are represented by $M$ equality constraints and $N$ inequality constraints. A comparison of (11) with ((5), (6), (7), (8), (9), and (10)) suggests that $h_{m}\left(x_{1}, x_{2}, \ldots, x_{K}\right)(m=1,2, \ldots, M)$ and $g_{n}\left(x_{1}, x_{2}, \ldots, x_{K}\right)$ $(n=1,2, \ldots, N)$ are analogous to the water balance and the regulating capacity constraints, respectively.

Dual values are applied to characterize the effects of operational constraints on optimal decisions [21, 22, 24]. In economic studies, dual values are also called shadow prices, which indicate the marginal increase of total profit by a one-unit increase in scarce resources [30]. Denoting the dual values of $h_{m}\left(x_{1}, x_{2}, \ldots, x_{K}\right)(m=1, \ldots, M)$ and $g_{n}\left(x_{1}, x_{2}, \ldots, x_{K}\right)(n=1, \ldots, N)$ as $\lambda_{m}$ and $\lambda_{M+n}$, respectively, the optimality conditions, that is, Karush-Kuhn-Tucker 
(KKT) conditions, of the optimal $\left[x_{1}^{*}, x_{2}^{*}, \ldots, x_{K}^{*}\right]$ are as follows [30]:

$$
\begin{gathered}
\lambda_{M+n} \geq 0 \quad(n=1, \ldots, N), \\
\lambda_{M+n} g_{n}\left(x_{1}^{*}, \ldots, x_{K}^{*}\right)=0 \quad(n=1, \ldots, N), \\
\left.\frac{\partial B}{\partial x_{k}}\right|_{x_{k}=x_{k}^{*}}=\left.\sum_{m=1}^{M} \lambda_{m} \frac{\partial h_{m}}{\partial x_{k}}\right|_{x_{k}=x_{k}^{*}}+\left.\sum_{n=1}^{N} \lambda_{M+n} \frac{\partial g_{n}}{\partial x_{k}}\right|_{x_{k}=x_{k}^{*}}, \\
(k=1, \ldots, K) .
\end{gathered}
$$

For convex optimization problems, (12) to (14) are both sufficient and necessary for $\left[x_{1}^{*}, x_{2}^{*}, \ldots, x_{K}^{*}\right]$. The economic implications of the three equations are as follows.

(1) Equation (12) is called a nonnegativity condition, which indicates that the dual value $\lambda_{M+n}(n=$ $1,2, \ldots, N)$ of scarce resource $g_{n}\left(x_{1}, x_{2}, \ldots, x_{K}\right)$ is nonnegative; that is, the increase in scarce resource potentially promotes the total profit.

(2) Equation (13) is called the complementary slackness condition, which indicates that $\lambda_{M+n}$ is positive only when the corresponding constraint is binding; that is, the resource has been entirely consumed, and a one-unit increase in $g_{n}\left(x_{1}, x_{2}, \ldots, x_{K}\right)$ promotes total profit by $\lambda_{M+n}$. Notably, (12) and (13) exclude $\lambda_{m}(m=$ $1,2, \ldots, M)$ because equality constraints are always binding and $\lambda_{m}$ is not subject to the conditions of nonnegativity and complementary slackness.

(3) Equation (14) is called the marginal value condition. $\partial B / \partial x_{k}$ is marginal profit from producing $x_{k} . \partial g_{m} / \partial x_{k}$ and $\partial h_{n} / \partial x_{k}$ indicate the marginal use of resources $g_{m}\left(x_{1}, x_{2}, \ldots, x_{K}\right)$ and $h_{n}\left(x_{1}, x_{2}, \ldots, x_{K}\right)$, respectively, in producing $x_{k}$. At the optimality, the marginal profit $\partial B / \partial x_{k}$ of producing $x_{k}$ must be equal to the marginal cost $\sum_{m=1}^{M} \lambda_{m}\left(\partial h_{m} / \partial x_{k}\right)+\sum_{n=1}^{N} \lambda_{M+n}\left(\partial g_{n} / \partial x_{k}\right)$, which is the sum of the marginal uses of resources multiplied by corresponding dual values.

Following the KKT conditions, we denote dual values for the total WA constraint (6) by $\lambda_{\mathrm{WA}}$; for release capacity constraints (7) and (8) by $\lambda_{\bar{r}, t}$ and $\lambda_{-r, t}(t=1, \ldots, H)$, respectively; and for storage capacity constraints (9) and (10) by $\lambda_{\bar{s}, t}$ and $\lambda_{-s, t}(t=1, \ldots, H-1)$, respectively. Equation (6) is an equality constraint that is always binding; thus, the corresponding dual value $\lambda_{\mathrm{WA}}$ indicates the marginal utility of WA in reservoir operation. Dual values corresponding to inequality constraints are explored based on (12) and (13). We derive that

$$
\begin{gathered}
\lambda_{\bar{s}, t} \geq 0, \\
\lambda_{-\underline{s}, t} \geq 0,
\end{gathered}
$$

and that

$$
\begin{gathered}
\lambda_{\bar{r}, t}\left(r_{t}-\bar{r}_{t}\right)=0, \\
\lambda_{-\underline{r}, t}\left(-r_{t}+\underline{r}_{t}\right)=0, \\
\lambda_{\bar{s}, t}\left[\left(s_{\text {ini }}+\sum_{i=1}^{t} q_{i}-\sum_{i=1}^{t} r_{i}\right)-\bar{s}_{t+1}\right]=0, \\
\lambda_{-\underline{s}, t}\left[\left(-s_{\text {ini }}-\sum_{i=1}^{t} q_{i}+\sum_{i=1}^{t} r_{i}\right)+\underline{s}_{t+1}\right]=0 .
\end{gathered}
$$

Equation (15) indicates that enhancing the reservoir regulating capacity can potentially improve total utility. Equation (16) indicates that $\lambda_{\bar{r}, t}, \lambda_{-r, t}, \lambda_{\bar{s}, t}$, and $\lambda_{-s, t}$ are positive only when the corresponding constraints of release and storage capacities are binding. Interpretations of the dual values are presented in Table 1.

Among the KKT conditions, (14) is related to optimal decisions. Equation (14) indicates that the optimality condition of $x_{k}$ accounts for dual values $\lambda_{m}(m=1,2, \ldots, M)$ and $\lambda_{M+n}(n=1,2, \ldots, N)$ only when $\partial h_{m} / \partial x_{k} \neq 0$ and $\partial g_{n} / \partial x_{k} \neq 0$; that is, producing $x_{k}$ consumes resources $h_{m}$ and $g_{n}$. Equation (14) yields the optimality condition of $r_{t}$. First, $r_{t}$ consumes WA and exists in (6). Second, $r_{t}$ is constrained by release capacity constraints (7) and (8). Third, $r_{t}$ affects reservoir storage $s_{i+1}(i=t, t+1, \ldots, H)$ in subsequent periods and is constrained by storage capacity constraints $(9-i)$ and $(10-i)(i=t, t+1, \ldots, H-1)$. The partial derivatives of $r_{t}$ in (6), (7), (8), $(9-i)$, and $(10-i)$ are 1,1 , $-1,-1$, and 1 , respectively. Therefore, the optimality condition of $r_{t}$ is jointly determined by $\lambda_{\mathrm{WA}}, \lambda_{\bar{r}, t}, \lambda_{-\underline{r}, t}, \lambda_{\bar{s}, i}$ and $\lambda_{-\underline{s}, i}(i=$ $t, t+1, \ldots, H-1)$ as follows:

$$
b_{t}^{\prime}\left(r_{t}\right)= \begin{cases}\lambda_{\mathrm{WA}}+\lambda_{\bar{r}, t}-\lambda_{-\underline{r}, t}-\sum_{i=t}^{H-1} \lambda_{\bar{s}, i}+\sum_{i=t}^{H-1} \lambda_{-s, i}, \\ \lambda_{\mathrm{WA}}+\lambda_{\bar{r}, t}-\lambda_{-\underline{\underline{r}, t},} \quad(t=1, \ldots, H-1), \\ \quad(t=H) .\end{cases}
$$

Equation (17) indicates the sequential nature of reservoir operation; that is, release in period $t$ affects WA, release capacity in period $t$, and storage capacity in subsequent periods. As a result, the dual values of WA, $\bar{r}_{t}$ and $-\underline{r}_{t}$, and $\bar{s}_{i+1}$ and $-\underline{s}_{i+1}(i=t, t+1, \ldots, H-1)$ must be considered to determine optimal $r_{t}$.

\section{Analysis of Reservoir Operation Optimization}

Release decisions have a balanced relationship, the sum of which is equal to the total WA. As a result, the dual value $\lambda_{\mathrm{WA}}$ of WA is linked to the marginal utilities

$$
\begin{aligned}
\lambda_{\bar{r}, t} & \geq 0, \\
\lambda_{-\underline{r}, t} & \geq 0,
\end{aligned}
$$


TABLE 1: Dual values of constraints in reservoir operation optimization.

\begin{tabular}{|c|c|}
\hline Dual value & Meaning of dual value \\
\hline$\overline{\lambda_{\mathrm{WA}}}$ & Marginal value of WA, for example, marginal utility from one unit increases in WA. \\
\hline$\lambda_{\bar{r}, t}(t=1,2, \ldots, H)$ & $\begin{array}{l}\text { Marginal value of } \bar{r}_{t} \cdot \lambda_{\bar{r}, t} \text { is positive when } r_{t}=\bar{r}_{t} \text {, and the value indicates utility gain from using one more } \\
\text { unit of water in period } t \text {. }\end{array}$ \\
\hline$\lambda_{-\underline{r}, t}(t=1,2, \ldots, H)$ & $\begin{array}{l}\text { Marginal value of }-\underline{r}_{t} \cdot \lambda_{-\underline{r}, t} \text { is positive when }-r_{t}=-\underline{r}_{t} \text {, and the value indicates utility gain from saving one } \\
\text { more unit of water in period } t \text {. }\end{array}$ \\
\hline$\lambda_{\bar{s}, t}(t=1,2, \ldots, H-1)$ & $\begin{array}{l}\text { Marginal value of } \bar{s}_{t+1} \cdot \lambda_{\bar{s}, t} \text { is positive when } s_{t+1}=\bar{s}_{t+1} \text {, and the value indicates utility gain from refilling } \\
\text { reservoir storage by one more unit at the beginning of period } t+1 \text {. }\end{array}$ \\
\hline$\lambda_{-s, t}(t=1,2, \ldots, H-1)$ & $\begin{array}{l}\text { Marginal value of }-\underline{s}_{t+1} \cdot \lambda_{-, t, t} \text { is positive when }-s_{t+1}=-\underline{s}_{t+1} \text {, and the value indicates utility gain from drawing } \\
\text { down reservoir storage by one more unit at the beginning of period } t+1 \text {. }\end{array}$ \\
\hline
\end{tabular}

$b_{t}^{\prime}\left(r_{t}\right)(t=1,2, \ldots, H)$ of release. Reformulating (17) yields the following:

$$
\lambda_{\mathrm{WA}}=\left\{\begin{array}{c}
b_{t}^{\prime}\left(r_{t}\right)-\lambda_{\bar{r}, t}+\lambda_{-\underline{r}, t}+\sum_{i=t}^{H-1} \lambda_{\bar{s}, i}-\sum_{i=t}^{H-1} \lambda_{-\underline{s}, i}, \\
(t=1,2, \ldots, H-1), \\
b_{t}^{\prime}\left(r_{t}\right)-\lambda_{\bar{r}, t}+\lambda_{-\underline{r}, t}, \quad(t=H) .
\end{array}\right.
$$

In (18), marginal utilities of release among different periods in water supply are always affected by the dual value $\lambda_{\mathrm{WA}}$ of WA. Dual values of release and storage capacity constraints also affect $b_{t}^{\prime}\left(r_{t}\right)$. This section discusses the effects of constraints on reservoir operation in detail on the basis of (18).

\subsection{Optimization without Binding Constraints of Release and} Storage Capacity. Consider a baseline Case 0 in which both release and storage capacity constraints are nonbinding; that is, the reservoir has enough capacity to regulate streamflow variability. Dual values of release and storage capacity constraints must be zero according to the complementary slackness condition (see (13) and (16)). As a result, (18) is transformed as follows:

$$
\lambda_{\mathrm{WA}}=\left\{\begin{array}{l}
b_{1}^{\prime}\left(r_{1}^{*}\right) \\
b_{2}^{\prime}\left(r_{2}^{*}\right) \\
\vdots \\
b_{H}^{\prime}\left(r_{H}^{*}\right) .
\end{array}\right.
$$

Equation (19) illustrates that optimal release decisions $\left[r_{1}^{*}, r_{2}^{*}, \ldots, r_{H}^{*}\right]$ exhibit equal marginal utilities. The case without binding release and storage capacity constraints corresponds to reservoirs with large capacities or regulating streamflow with low variability $[10,29,31]$. Multipleperiod reservoir operation can be conceptualized as a onestage model, as shown in Figure 2. Total WA, and not $\left[q_{1}, q_{2}, \ldots, q_{H}\right]$, determines the release decisions in the stage lasting from periods 1 to $H$. Optimal decisions follow the marginal value principle, which yields maximum utility.

There are in total $H+1$ unknown variables, that is, $\left[r_{1}^{*}, r_{2}^{*}, \ldots, r_{H}^{*}\right]$ and $\lambda_{\mathrm{WA}}$. Equation (19) comprises $H$ equations. In addition, the water balance relationship can be described as follows:

$$
\sum_{t=1}^{H} r_{t}^{*}=\mathrm{WA}=\sum_{t=1}^{H} q_{t}+\left(s_{\mathrm{ini}}-s_{\mathrm{end}}\right) .
$$

Therefore, $\left[r_{1}^{*}, r_{2}^{*}, \ldots, r_{H}^{*}\right]$ and $\lambda_{\mathrm{WA}}$ can be determined by using (19) and (20). The optimal decision for special cases where the utility functions of all periods are identical is to allocate total WA evenly among the periods as follows:

$$
r_{1}^{*}=\cdots=r_{H}^{*}=\frac{\mathrm{WA}}{H} .
$$

The dual value of WA is expressed as follows:

$$
\lambda_{\mathrm{WA}}=b^{\prime}\left(\frac{\mathrm{WA}}{H}\right) \text {. }
$$

As shown in (19) to (22), total WA is the determinant of $\left[r_{1}^{*}, r_{2}^{*}, \ldots, r_{H}^{*}\right]$ and $\lambda_{\mathrm{WA}}$ in Case 0 . These equations suggest that WA and its dual value $\lambda_{\mathrm{WA}}$ have a negative monotonic relationship. Marginal utility $\lambda_{\mathrm{WA}}$ from a one-unit increase in WA diminishes with WA in water supply reservoir operation. Moreover, WA and $\left[r_{1}^{*}, r_{2}^{*}, \ldots, r_{H}^{*}\right]$ have a positive monotonic relationship. $r_{t}^{*}$ varies with WA. According to the marginal value principle, decreasing WA reduces release and increasing WA increases release.

3.2. Optimization with Binding Constraints of Release Capacity. Despite the monotonic relationship between $r_{t}^{*}$ and WA, $r_{t}^{*}$ can be constrained by release capacity constraints $((7)$ and (8)). Incorporating dual values of constraints $r_{t} \leq \bar{r}_{t}$ and $-r_{t} \leq-\underline{r}_{t}(t=1,2, \ldots, H)$ into (19) yields the following:

$$
\lambda_{\mathrm{WA}}=b_{t}^{\prime}\left(r_{t}^{*}\right)-\lambda_{\bar{r}, t}+\lambda_{-\underline{r}, t}, \quad(t=1, \ldots, H) .
$$

In (23), either $\lambda_{\bar{r}, t}$ or $\lambda_{-r, t}$ is zero because $r_{t}=\bar{r}_{t}$ and $r_{t}=\underline{r}_{t}$ cannot occur simultaneously. Basing on Case 0 , we analyze Cases 1 and 2, in which $r_{t} \leq \bar{r}_{t}$ and $-r_{t} \leq-\underline{r}_{t}$ are binding, respectively.

In Case 1, we examine the binding constraint of upper release capacity, which occurs with ample WA and large storage capacity. In addition to the diminishing marginal utility of $r_{t}$ (i.e., $b_{t}^{\prime \prime}<0$ ), we also assume that $b_{t}^{\prime}\left(\bar{r}_{t}\right)=0$, that is, marginal utility of release in period $t$, becomes zero when the maximum demand is satisfied $[25,28]$. We suppose that $r_{t}^{*}$ reaches the upper bound $\bar{r}_{t}$ in period $t_{1}$. Incorporating the corresponding dual value $\lambda_{\bar{r}, t_{1}}$ yields the following optimality condition:

$$
\lambda_{\mathrm{WA}}=\left\{\begin{array}{l}
b_{t_{1}}^{\prime}\left(\bar{r}_{t_{1}}\right)-\lambda_{\bar{r}, t_{1}}, \\
b_{i}^{\prime}\left(r_{i}^{*}\right),
\end{array} \quad\left(i=1, \ldots, H ; i \neq t_{1}\right),\right.
$$




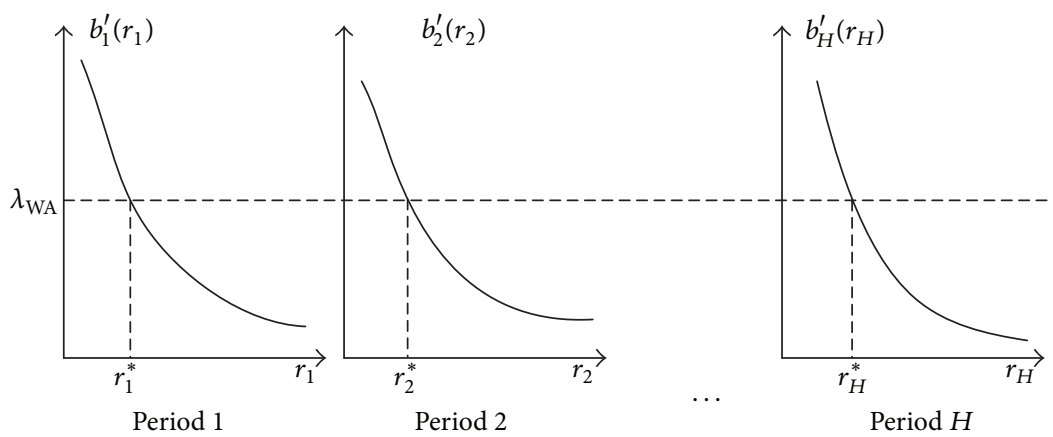

FIGURE 2: Release among periods exhibits equal marginal utilities when release and storage capacity constraints are nonbinding (Case 0).
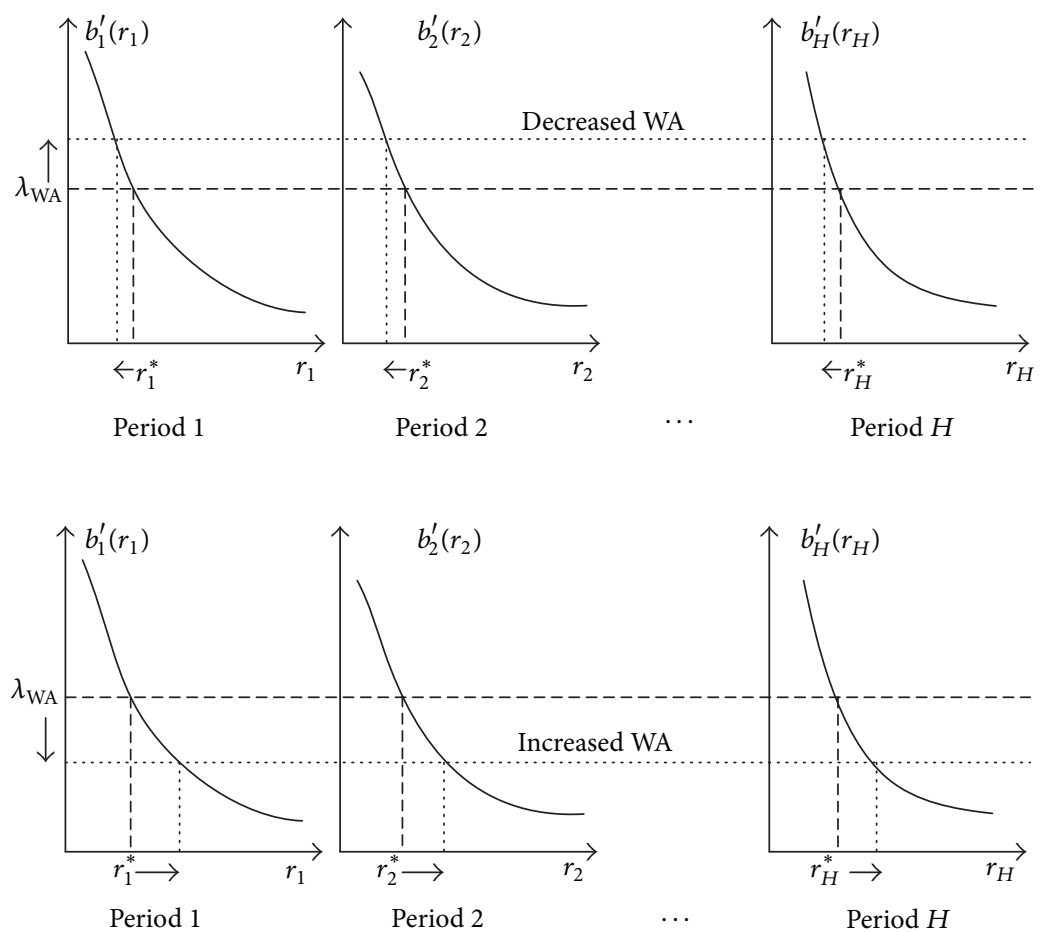

Figure 3: A positive monotonic relationship exhibited by WA and $\left[r_{1}^{*}, r_{2}^{*}, \ldots, r_{H}^{*}\right]$, and a negative monotonic relationship exhibited by WA and its dual value $\lambda_{\mathrm{WA}}$ (Case 0 ).

where $b_{t_{1}}^{\prime}\left(\bar{r}_{t_{1}}\right)$ is zero, indicating that $\lambda_{\mathrm{WA}}=-\lambda_{\bar{r}, t_{1}}$. Considering that both $\lambda_{\mathrm{WA}}$ and $\lambda_{\bar{r}, t_{1}}$ are nonnegative (Table 1), we have $\lambda_{\mathrm{WA}}=-\lambda_{\bar{r}, t_{1}}=0$ and

$$
b_{i}^{\prime}\left(r_{i}^{*}\right)=0, \quad r_{i}^{*}=\bar{r}_{i}, \quad(i=1, \ldots, H) .
$$

Therefore, maximum demands in other periods must also be satisfied (Figure 4 ) if the maximum demand in period $t_{1}$ is satisfied. This result is because the storage capacity constraint is not yet binding and because water supply follows the marginal value principle. WA satisfies the maximum demands, and $r_{t}^{*}(t=1,2, \ldots, H)$ reaches the upper bound. In Case 1, further increase in WA causes spill and ceases contribution to the total utility; that is, $\lambda_{\mathrm{WA}}$ becomes zero.

Based on Case 1, we analyze Case 2, where $r_{t}^{*}$ reaches the lower bound $\underline{r}_{t}$ in period $t_{2}$. Case 2 occurs under drought. We obtain the following optimality condition that is analogous to (24):

$$
\lambda_{\mathrm{WA}}=\left\{\begin{array}{l}
b_{t_{2}}^{\prime}\left(r_{t_{2}}^{*}\right)+\lambda_{-\underline{r}, t_{2}}, \\
b_{i}^{\prime}\left(r_{i}^{*}\right),
\end{array} \quad\left(i=1, \ldots, H ; i \neq t_{2}\right) .\right.
$$

The relationships among $b_{t_{2}}^{\prime}\left(\underline{r}_{t_{2}}\right), \lambda_{\mathrm{WA}}$, and $\lambda_{-\underline{r} t_{2}}$ are illustrated in the upper part of Figure 5. Although only the minimum water requirement is satisfied in period $t_{2}$, reducing release remains beneficial because its utility gain $\lambda_{\mathrm{WA}}$ is higher than the opportunity $\cos t b_{t_{2}}^{\prime}\left(\underline{r}_{t_{2}}\right)$. However, this reduction is constrained by the minimum requirement constraint $-r_{t_{2}} \leq-\underline{r}_{t_{2}}\left(r_{t_{2}} \geq \underline{r}_{t_{2}}\right)$. The corresponding dual value is as follows:

$$
\lambda_{-\underline{r}, t_{2}}=\lambda_{\mathrm{WA}}-b_{t_{2}}^{\prime}\left(\underline{r}_{t_{2}}\right) .
$$



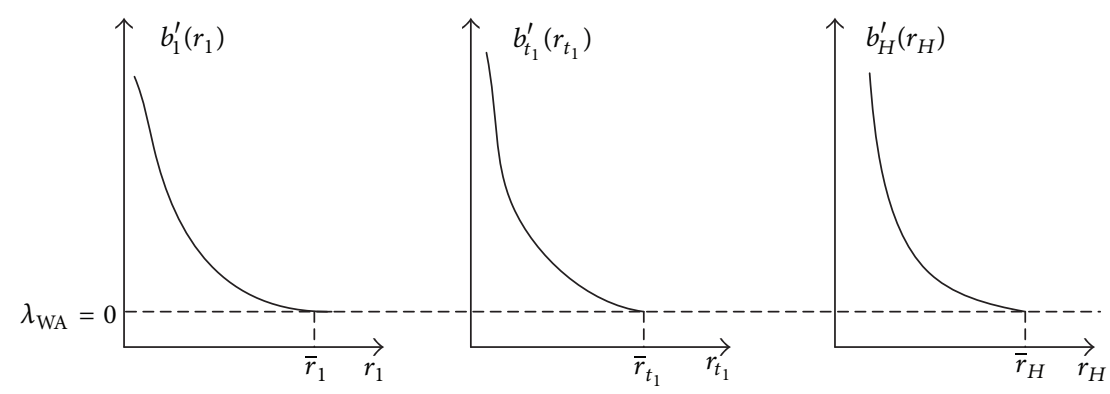

Period 1

Period $t_{1}$

Period $H$
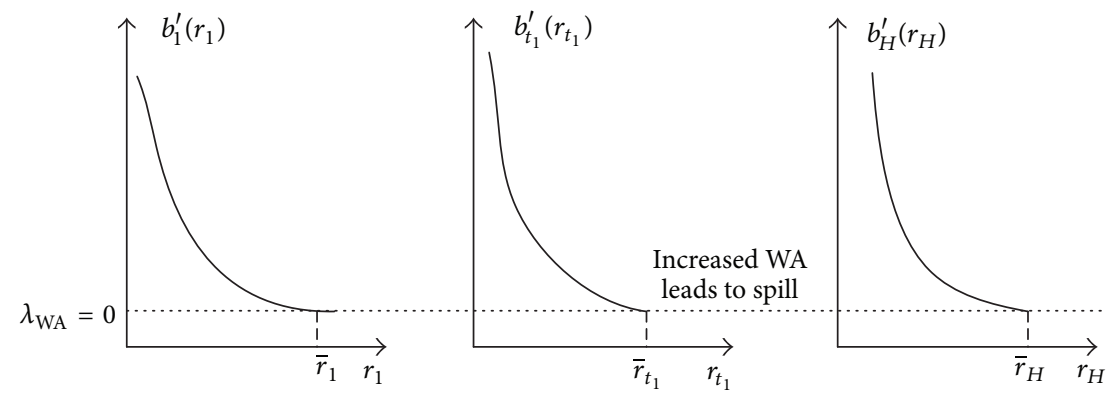

Period 1

Period $t_{1}$

Period $H$

FIGURE 4: The binding constraint of the upper release capacity hinders increase in release because of increased WA and causes spill (Case 1).
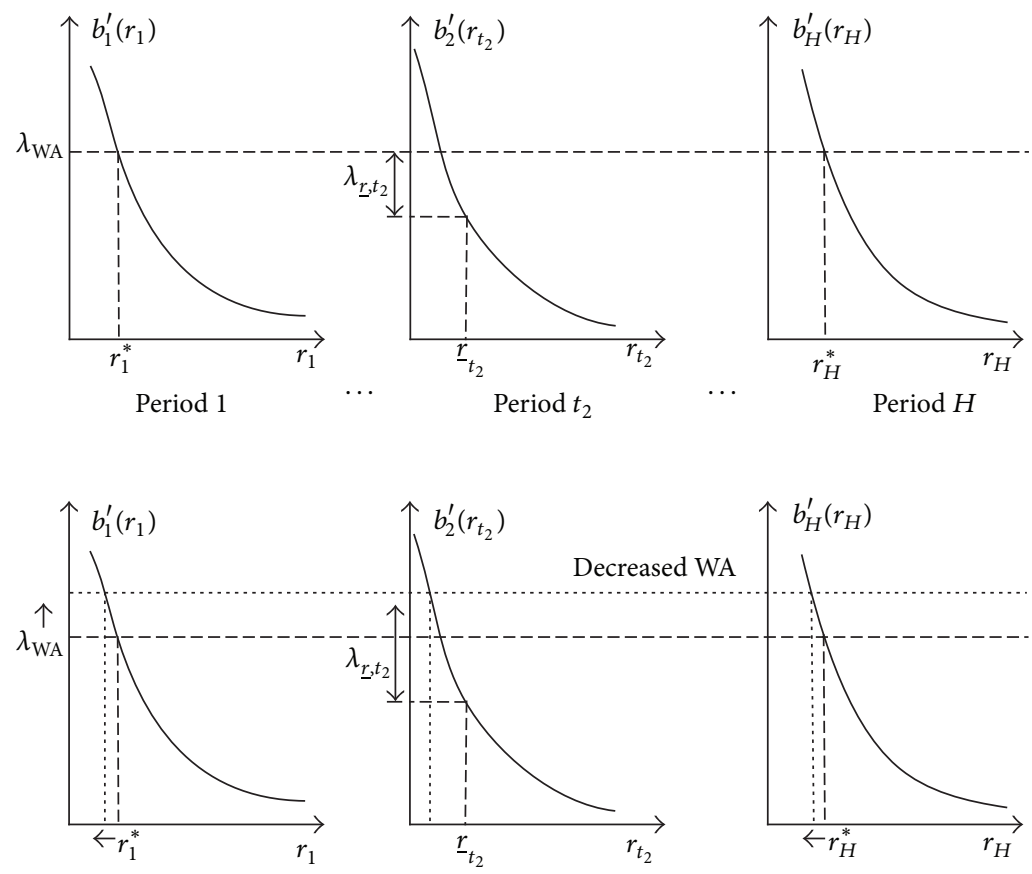

Period 1
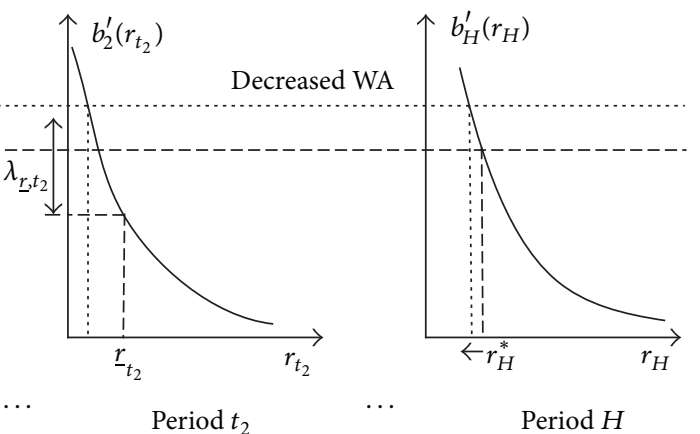

FIGURE 5: The binding constraint of the low release capacity in period $t_{2}$ hinders the reduction of $r_{t_{1}}$ decreased WA (Case 2).

$\lambda_{-\underline{r}, t_{2}}$ indicates the marginal value of $-\underline{r}_{t}$ and the net utility gain from reducing one unit of water in period $t_{2}$. In Case 2 , decreasing the total WA reduces $r_{i}^{*}\left(i=1, \ldots, H ; i \neq t_{2}\right)$ and increases $\lambda_{-\underline{r}, t_{2}}$, but $r_{t_{2}}^{*}$ remains $\underline{r}_{t_{2}}$, as shown in the lower part of Figure 5.
A comparison of Cases 1 and 2 with baseline Case 0 reveals that total WA remains the major determinant of $\left[r_{1}^{*}, r_{2}^{*}, \ldots, r_{H}^{*}\right]$. The cases with bind release capacity constraint can still be characterized as a one-stage model. However, the release capacity constraint affects single-period 
release and can block the increase (decrease) of release with increasing (decreasing) WA. The upper release capacity constraint binds under sufficient WA. In this case, the maximum demands in all periods are satisfied, and further increase in WA leads to spill. The lower release capacity constraint binds under drought conditions when WA is very limited and forces reservoir release to satisfy the minimum water requirement. Notably, further decrease in WA makes the constraint binding in more periods and finally makes (1) and ((5), (6), (7), (8), (9), and (10)) infeasible; that is, WA is insufficient to satisfy the minimum water requirements in the periods.

\subsection{Optimization with Binding Constraints of Storage Capac-} ity. Reservoir storage carries over WA between periods. During high-flow periods, storage is refilled to reserve water for future use; during low-flow periods, storage is drawn down to supply water. The storage refill and drawing down are bounded by the upper and lower storage capacity constraints, respectively. Incorporating dual values of the storage capacity constraints yields the following:

$$
\begin{aligned}
\lambda_{\mathrm{WA}} & =b_{H}^{\prime}\left(r_{H}^{*}\right) \\
& =b_{H-1}^{\prime}\left(r_{H-1}^{*}\right)+\lambda_{\bar{s}, H-1}-\lambda_{-\underline{s}, H-1} \\
& =b_{H-2}^{\prime}\left(r_{H-2}^{*}\right)+\lambda_{\bar{s}, H-2}-\lambda_{-\underline{s}, H-2}+\lambda_{\bar{s}, H-1}-\lambda_{-\underline{s}, H-1} \\
& =\cdots \\
& =b_{1}^{\prime}\left(r_{1}^{*}\right)+\sum_{t=1}^{H-1} \lambda_{\bar{s}, t}-\sum_{t=1}^{H-1} \lambda_{-\underline{s}, t} .
\end{aligned}
$$

Releasing $r_{t}$ affects storage $s_{t+1}, s_{t+2}, \ldots, s_{H}$ in subsequent periods; thus, the optimality condition of $r_{t}$ considers dual values of storage capacity constraints in subsequent periods. The effects of the storage capacity constraint can be more extensive compared with those of the release capacity constraint affecting single-period decisions (23). In (28), either $\lambda_{\bar{s}, t}$ or $\lambda_{-\underline{s}, t}$ is zero because $s_{\text {ini }}+\sum_{i=1}^{t} q_{i}-\sum_{i=1}^{t} r_{i}=\bar{s}_{t+1}$ (see (9)) and $s_{\text {ini }}+\sum_{i=1}^{t} q_{i}-\sum_{i=1}^{t} r_{i}=\underline{s}_{t+1}$ (see (10)) cannot be binding simultaneously. By using (28), we analyze Cases 3, 4 , and 5, where the upper and lower storage capacity constraints are binding.

In Case 3, we suppose that an upper storage capacity constraint bounds in period $t_{3}$ as follows:

$$
s_{t_{3}+1}=s_{\text {ini }}+\sum_{i=1}^{t_{3}} q_{i}-\sum_{i=1}^{t_{3}} r_{i}^{*}=\bar{s}_{t_{3}+1} .
$$

This binding occurs when high-flow periods $\left[1,2, \ldots, t_{3}\right]$ precede low-flow periods $\left[t_{3}+1, t_{3}+2, \ldots, H\right]$. Storage is refilled to store water, which is constrained by the upper storage capacity in stage 1 . Following (28), we derive the following optimality condition:

$$
\lambda_{\mathrm{WA}}= \begin{cases}b_{i}^{\prime}\left(r_{i}^{*}\right)+\lambda_{\bar{s}, t_{3}}, & \left(i=1, \ldots, t_{3}\right), \\ b_{i}^{\prime}\left(r_{i}^{*}\right), & \left(i=t_{3}+1, \ldots, H\right) .\end{cases}
$$

The binding storage capacity constraint at period $t_{3}$ divides the $H$ periods into stage 1 (periods $\left[1,2, \ldots, t_{3}\right]$ ) and stage 2 (periods $\left.\left[t_{3}+1, t_{3}+2, \ldots, H\right]\right)$. Marginal utilities of release in either stage are equal depending on the WA in that stage and follow the marginal value principle.

The marginal utilities of WA in the two stages generate a gap that indicates the economic incentive of storing water in stage 1 ; that is, the opportunity cost of storing water in stage 1 is lower than the potential utility of supplying water in stage 2. Reservoir storage is refilled until it is bounded by the upper storage capacity $\bar{s}_{t_{3}+1}$. Dual value $\lambda_{\bar{s}, t_{3}}$ indicates the marginal value of $\bar{s}_{t_{3}+1}$, that is, utility gain from refilling reservoir storage by one more unit. The relationships among $b_{i}^{\prime}\left(r_{i}^{*}\right)\left(i=1, \ldots, t_{3}\right), b_{i}^{\prime}\left(r_{i}^{*}\right)\left(i=t_{3}+1, \ldots, H\right)$, and $\lambda_{\bar{s}, t_{3}}$ are presented in the upper part of Figure 6. As shown in the figure, decreased WA in stage 2 increases potential utility gain from carrying over water to stage 2 , as indicated by the increased marginal value $\lambda_{\bar{s}, t_{3}}$ for $\bar{s}_{t_{3}+1}$ but cannot affect decisions $\left[r_{1}^{*}, r_{2}^{*}, \ldots, r_{t_{3}}^{*}\right]$ in stage 1 . This result is attributed to the case where the limit $\bar{s}_{t_{3}+1}$ of storage refill has been reached (see (29)). As shown in Figure 6, water can no longer be carried over from stage 1 to stage 2 , even if WA has higher marginal value in stage 2 than in stage 1 .

Based on Case 3, we analyze Case 4 where a binding constraint of lower storage capacity occurs in period $t_{4}$ as follows:

$$
-s_{t_{4}+1}=-\left(s_{\text {ini }}+\sum_{i=1}^{t_{4}} q_{i}-\sum_{i=1}^{t_{4}} r_{i}^{*}\right)=-\underline{s}_{t_{4}+1} .
$$

Equation (31) is equivalent to $s_{t_{4}+1}=s_{\text {ini }}+\sum_{i=1}^{t_{4}} q_{i}-\sum_{i=1}^{t_{4}} r_{i}^{*}=$ $\underline{s}_{t_{4}+1}$. This case occurs when low-flow periods $\left[1,2, \ldots, t_{4}\right]$ (denoted as stage 1) are succeeded by high-flow periods $\left[t_{4}+\right.$ $\left.1, t_{4}+2, \ldots, H\right]$ (stage 2). Equation (28) yields the following:

$$
\lambda_{\mathrm{WA}}= \begin{cases}b_{i}^{\prime}\left(r_{i}^{*}\right)-\lambda_{-\underline{s}, t_{4}}, & \left(i=1, \ldots, t_{4}\right), \\ b_{i}^{\prime}\left(r_{i}^{*}\right), & \left(i=t_{4}+1, \ldots, H\right) .\end{cases}
$$

Marginal utilities of release in stage 1 are the same and are higher than the marginal utilities of release in stage 2 . Thus, storage is drawn down to supply as much water as possible in stage 1 . Dual value $\lambda_{s, t_{4}}$ indicates the marginal value of $-\underline{s}_{t+1}$ and utility gain from decreasing lower storage bound by one more unit, which allows for the carry-over of additional water from stage 2 to stage 1 . The relationships among $b_{i}^{\prime}\left(r_{i}^{*}\right)\left(i=1, \ldots, t_{4}\right), b_{i}^{\prime}\left(r_{i}^{*}\right)\left(i=t_{4}+1, \ldots, H\right)$, and $\lambda_{\underline{s}, t_{4}}$ are presented in the upper part of Figure 7. In Case 4, increased WA in stage 2 leads to higher potential utility gain from carrying over WA from stage 2 to stage 1 , as indicated by the increased marginal value $\lambda_{\bar{s}, t_{3}}$ for $-\underline{s}_{t_{4}+1}$ (lower part of Figure 7). However, increased WA in stage 2 does not affect decisions $\left[r_{1}^{*}, r_{2}^{*}, \ldots, r_{t_{4}}^{*}\right]$ because the limit $-\underline{s}_{t_{4}+1}$ of storage drawn down has been reached.

The binding constraint of storage capacity leads to multistage reservoir operation. For Cases 3 and 4, water carried over between the two stages is driven by the marginal value of water but constrained by storage capacity $[21,22,28]$. Based on the two-stage cases, we consider Case 5 where the binding 

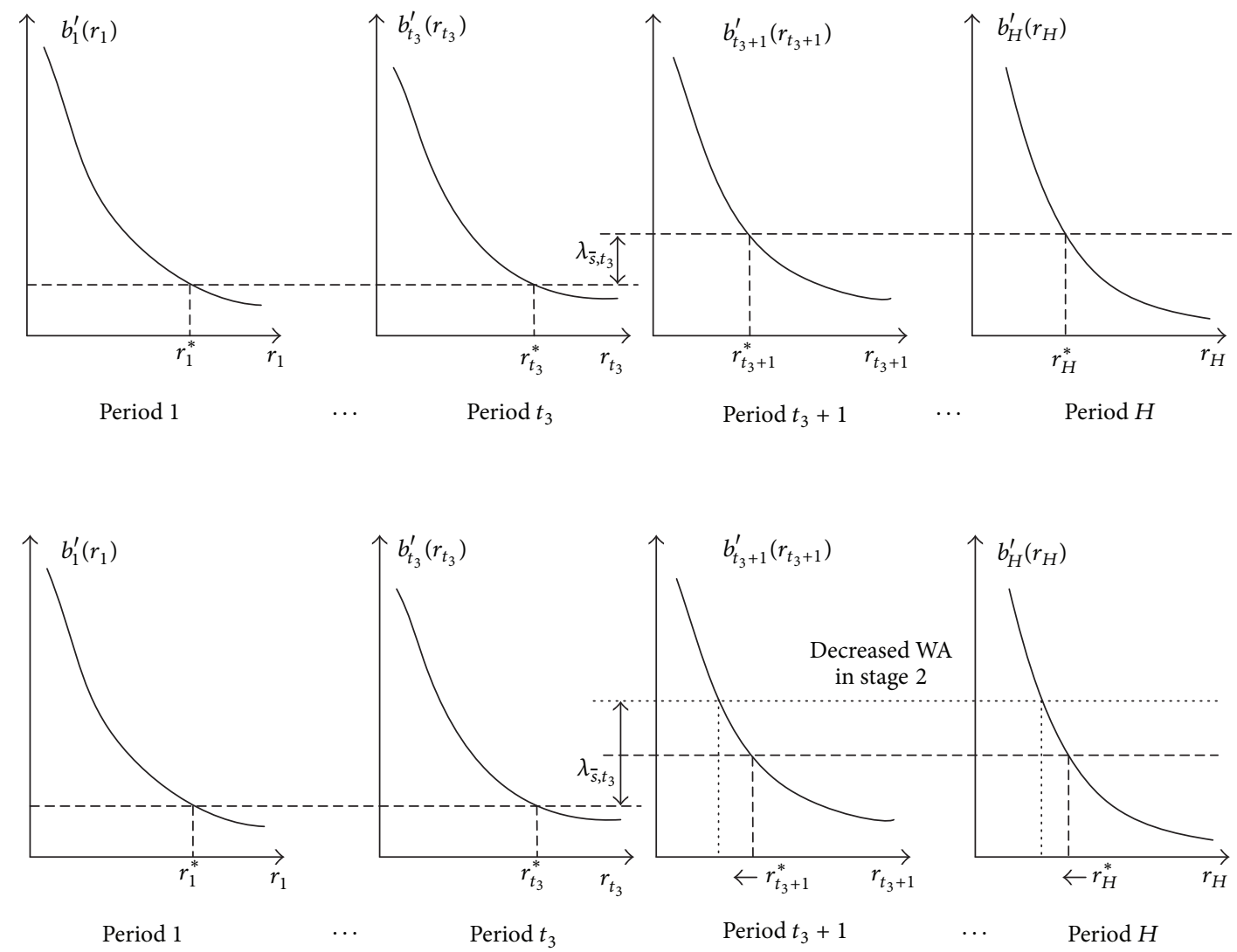

FIGURE 6: The binding constraint of the upper storage capacity in period $t_{3}$, that is, $s_{t_{3}+1}=s_{\text {ini }}+\sum_{i=1}^{t_{3}} q_{i}-\sum_{i=1}^{t_{3}} r_{i}^{*}=\bar{s}_{t_{3}+1}$, blocks carrying-over water availability from stage 1 (periods 1 to $t_{3}$ ) to stage 2 (periods $t_{3}+1$ to $H$ ), even though water has higher marginal value in stage 2 than in stage 1 (Case 3).

constraints of the upper and lower storage capacities occur in periods $t_{3}$ and $t_{4}$, respectively. This case considers three stages of reservoir operation as follows:

$$
\begin{gathered}
s_{t_{3}+1}=s_{\text {ini }}+\sum_{i=1}^{t_{3}} q_{i}-\sum_{i=1}^{t_{3}} r_{i}^{*}=\bar{s}_{t_{3}+1}, \\
-s_{t_{4}+1}=-\left(s_{\text {ini }}+\sum_{i=1}^{t_{4}} q_{i}-\sum_{i=1}^{t_{4}} r_{i}^{*}\right)=-\underline{s}_{t_{4}+1} .
\end{gathered}
$$

If $t_{3}<t_{4}$, then high-flow periods $\left[1,2, \ldots, t_{3}\right]$ (denoted as stage 1$)$ are succeeded by low-flow periods $\left[t_{3}+1, t_{3}+2, \ldots, t_{4}\right]$ (stage 2 ), which are followed by high-flow periods $\left[t_{4}+1, t_{4}+\right.$ $2, \ldots, H]$ (stage 3 ). Thus, the reservoir storage is refilled in stage 1 to carry over water to stage 2 ; storage is then drawn down to supply water in stage 2 and refilled again in stage 3 . Equation (28) yields the following:

$$
\lambda_{\mathrm{WA}}= \begin{cases}b_{i}^{\prime}\left(r_{i}^{*}\right)+\lambda_{\bar{s}, t_{3}}-\lambda_{-\underline{s}, t_{4}}, & \left(i=1, \ldots, t_{3}\right), \\ b_{i}^{\prime}\left(r_{i}^{*}\right)-\lambda_{-\underline{s}, t_{4}}, & \left(i=t_{3}+1, \ldots, t_{4}\right), \\ b_{i}^{\prime}\left(r_{i}^{*}\right), & \left(i=t_{4}+1, \ldots, H\right) .\end{cases}
$$

Equation (34) indicates that marginal utilities of release in any stage are equal (the upper part of Figure 8). According to
Case 4 , decisions in stages 1 and 2 are not affected by increased WA in stage 3 (the middle part of Figure 8). Moreover, Case 3 indicates that decisions in stage 1 are not affected by decreased WA in stages 2 and 3 (the lower part of Figure 8). Therefore, release decisions in stage 1 are not affected by either the decrease or increase of WA in stage 3. This result can be attributed to the fact that the binding constraint of upper (lower) storage capacity at period $t_{3}\left(t_{4}\right)$ blocks the effect of decreased (increased) WA in stage 3. A similar three-stage model wherein decisions in stage 1 are unaffected by WA in stage 3 can be observed when $t_{4}<t_{3}$.

A comparison of Cases 3, 4, and 5 with Cases 0,1 , and 2 reveals that binding storage capacity constraints result in multistage reservoir operation. WA in one stage remains an important determinant of that stage's release decisions, which exhibit equal marginal utilities (marginal value principle). However, the marginal utilities of WA in two consecutive stages generate a gap because of the binding storage capacity constraint and is thus indicated by the corresponding dual value. The upper storage capacity sets the limit of storage refill that carries over WA from one stage to its subsequent stages, and the binding of this storage capacity blocks the effect of decreased WA in subsequent stages on release decisions in preceding stages. By comparison, the lower storage capacity sets the limit of storage drawn down, and its binding blocks 

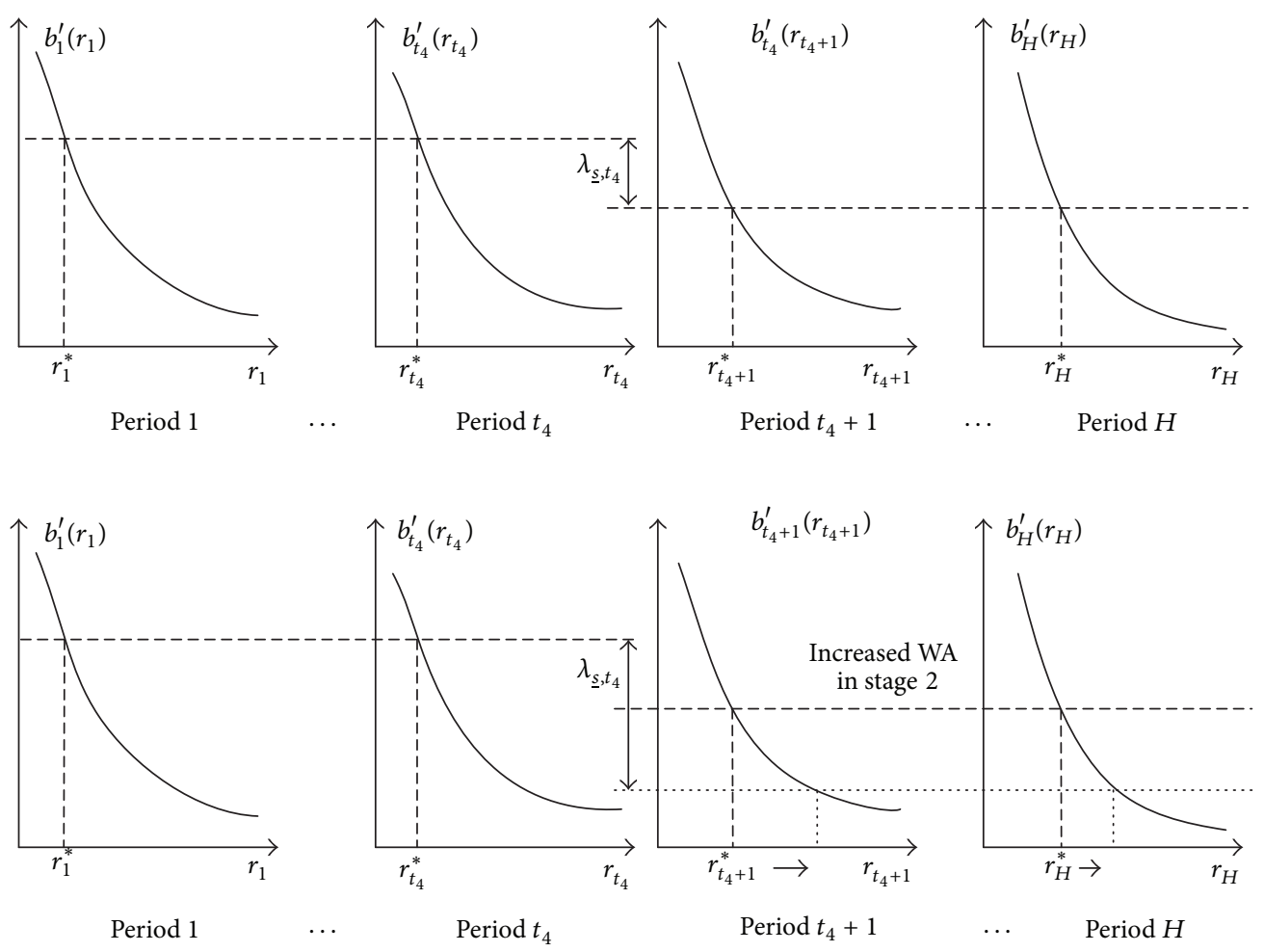

FIGURE 7: The binding constraint of the lower storage capacity in period $t_{4}$, that is, $-s_{t_{4}+1}=-\left(s_{\text {ini }}+\sum_{i=1}^{t_{4}} q_{i}-\sum_{i=1}^{t_{4}} r_{i}^{*}\right)=-\underline{s}_{t_{4}+1}$, blocks carrying over water availability from stage 2 (periods $t_{4}+1$ to $H$ ) to stage 1 (periods 1 to $t_{4}$ ), even though water has higher marginal value in stage 1 than in stage 2 (Case 4$)$.

the effect of increased WA in subsequent stages. Dual value of the binding storage capacity constraint indicates utility gain from one unit of additional storage carried over between stages.

3.4. Implications from Mathematical Analysis. We detail the effects of water balance, release capacity, and storage capacity constraints on water supply reservoir operation. The onestage, two-stage, and three-stage formulations of reservoir operation result from the effects of the constraints (Table 2). Cases 0,1 , and 2 have one-stage formulation. Optimal release decisions from periods 1 to $H$ depend on total WA and follow the marginal value principle. In Cases 3 and 4, reservoir operation becomes a two-stage problem. Although optimal release decisions exhibit equal marginal utilities in either stage 1 or stage 2 , the marginal utilities of water in the two stages generate a gap. This gap indicates the marginal value of storage capacity that allows for the carry-over of water between stages. Case 5 has three stages of reservoir operation, where release decisions in stage 1 are not affected by the change in WA in stage 3 because the binding upper (lower) storage capacity blocks the effect of decreased (increased) WA in subsequent stages on release decisions in preceding stages. In reservoir operation, more binding constraints can result in more stages. The six cases generalize the effects of constraints on multiple-period reservoir operation.

\section{Extended Analysis}

The analysis above highlights the importance of WA in one stage to release decisions in that stage. In decision-making, WA is usually estimated based on streamflow forecast and ending storage $[9,32,33]$. Considering forecast uncertainty and variations in ending storage, we have the following:

$$
\begin{aligned}
\mathrm{EWA} & =\sum_{t=1}^{H} f_{t}+\left(s_{\mathrm{ini}}-s_{\mathrm{end}}^{\prime}\right) \\
& =\mathrm{WA}+\left(\sum_{t=1}^{H} f_{t}-\sum_{t=1}^{H} q_{t}\right)-\left(s_{\text {end }}^{\prime}-s_{\text {end }}\right)
\end{aligned}
$$

where EWA denotes the estimation of water availability. The gap between the EWA and the actual WA comprises $\sum_{t=1}^{H} f_{t}-$ $\sum_{t=1}^{H} q_{t}\left(f_{t}\right.$ denotes forecast of $\left.q_{t}\right)$ due to forecast uncertainty and $s_{\text {end }}^{\prime}-s_{\text {end }}$ due to the variations in $s_{\text {end }}^{\prime}$ from the predefined $s_{\text {end }}$. This section explores the effects of forecast uncertainty and ending storage.

4.1. Effect of Forecast Uncertainty. Forecast uncertainty leads to bias in EWA. Considering the forecast uncertainty $\left(s_{\text {end }}^{\prime}=s_{\text {end }}\right)$ and denoting $r_{t}^{\prime}$ by period $t$ 's release decision 


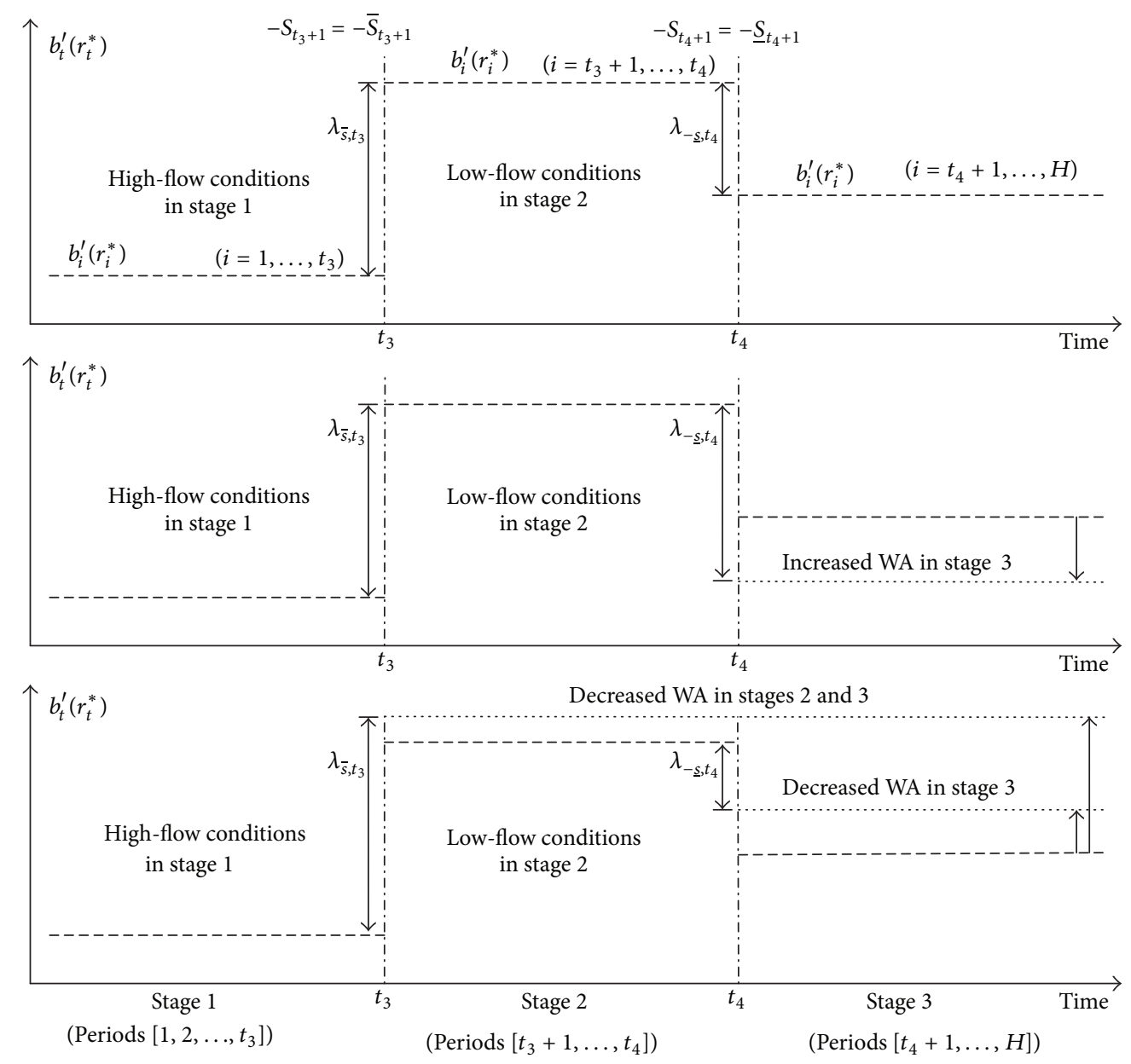

FIGURE 8: The binding constraints of the lower storage capacity in period $t_{3}$ and upper storage capacity in period $t_{4}$, respectively, block the effects of increased and decreased WA in stage 3 on operation decisions in stage 1.

TABLE 2: Characteristics and properties of operation decisions in the six cases.

\begin{tabular}{|c|c|c|c|}
\hline Case & Formulation & Characteristics & Properties \\
\hline 0 & One-stage (Figures 2 and 3) & $\begin{array}{l}\text { No binding release and storage capacity } \\
\text { constraints (Figure } 2 \text { ) }\end{array}$ & $\begin{array}{l}\text { Release decisions depend on total WA and follow the } \\
\text { marginal value principle }\end{array}$ \\
\hline 1 & One-stage (Figure 4) & $\begin{array}{l}\text { Upper release capacity constraint binding in } \\
\text { period } t_{1} \text { and also in other periods (Figure } 4 \text { ) }\end{array}$ & Increased total WA leads to spill \\
\hline 2 & One-stage (Figure 5) & $\begin{array}{l}\text { Lower release capacity constraint binding in } \\
\left.\text { period } t_{2} \text { (Figure } 5\right)\end{array}$ & $\begin{array}{l}\text { Minimum requirement is satisfied in period } t_{2} \text {, which } \\
\text { remains with decreased total WA }\end{array}$ \\
\hline 3 & Two-stage (Figure 6) & $\begin{array}{l}\text { Upper storage capacity constraint binding in } \\
\text { period } t_{3}(29)\end{array}$ & $\begin{array}{l}{\left[r_{1}^{*}, r_{2}^{*}, \ldots, r_{t_{3}}^{*}\right] \text { in stage } 1 \text { remain unchanged when WA }} \\
\left.\text { in periods }\left[t_{3}+1, t_{3}+2, \ldots, H\right] \text { (stage } 2\right) \text { decreases }\end{array}$ \\
\hline 4 & Two-stage (Figure 7) & $\begin{array}{l}\text { Lower storage capacity constraint binding in } \\
\text { period } t_{4}(31)\end{array}$ & $\begin{array}{l}{\left[r_{1}^{*}, r_{2}^{*}, \ldots, r_{t_{4}}^{*}\right] \text { in stage } 1 \text { remain unchanged when WA }} \\
\text { in periods }\left[t_{4}+1, t_{4}+2, \ldots, H\right](\text { stage } 2) \text { increases }\end{array}$ \\
\hline 5 & Three-stage (Figure 8) & $\begin{array}{l}\text { Upper and lower storage capacity constraints } \\
\left.\text { binding in periods } t_{3} \text { and } t_{4} \text {, respectively ( } 33\right)\end{array}$ & $\begin{array}{l}{\left[r_{1}^{*}, r_{2}^{*}, \ldots, r_{t}^{*}\right]\left(t=\min \left(t_{3}, t_{4}\right)\right) \text { in stage } 1 \text { are not affected }} \\
\text { by either the decrease or increase in WA in periods } \\
{[T+1, T+2, \ldots, H]\left(T=\max \left(t_{3}, t_{4}\right)\right)(\text { stage } 3)}\end{array}$ \\
\hline
\end{tabular}

under EWA, the water balance relationship yields the following:

$$
\sum_{t=1}^{H} r_{t}^{\prime}=\mathrm{EWA}=\mathrm{WA}+\left(\sum_{t=1}^{H} f_{t}-\sum_{t=1}^{H} q_{t}\right)
$$

Forecast uncertainty leads to either the overestimation $\left(\sum_{t=1}^{H} f_{t}>\sum_{t=1}^{H} q_{t}\right)$ or underestimation $\left(\sum_{t=1}^{H} f_{t}<\sum_{t=1}^{H} q_{t}\right)$ of WA, which should affect release decisions.

In Case 0, the reservoir operation has a one-stage formulation. Release decisions depend on total WA and follow 
the marginal value principle; that is, $b_{1}^{\prime}\left(r_{1}^{\prime}\right)=b_{2}^{\prime}\left(r_{2}^{\prime}\right)=$ $\cdots=b_{H}^{\prime}\left(r_{H}^{\prime}\right)=\lambda_{\mathrm{EWA}}$. Therefore, the following is derived (Appendix):

$$
r_{t}^{\prime}-r_{t}^{*}=\frac{1 / b_{t}^{\prime \prime}\left(r_{t}^{*}\right)}{\sum_{i=1}^{H} 1 / b_{i}^{\prime \prime}\left(r_{t}^{*}\right)}\left(\sum_{t=1}^{H} f_{t}-\sum_{t=1}^{H} q_{t}\right) \quad(t=1, \ldots, H) .
$$

Equation (37) illustrates a positive monotonic relationship between $r_{t}^{\prime}-r_{t}^{*}$ and $\sum_{t=1}^{H} f_{t}-\sum_{t=1}^{H} q_{t}$. If $\sum_{t=1}^{H} f_{t}>\sum_{t=1}^{H} q_{t}$, then $r_{t}^{\prime}>r_{t}^{*}$; as $r_{t}$ in $b_{t}\left(r_{t}\right)$ exhibits diminishing marginal utility, we also have $\lambda_{\text {EWA }}<\lambda_{\text {WA }}$. The indication is that, when future streamflow is overestimated, more water will be used than the optimal value and marginal values of water are underestimated. On the contrary, when future streamflow is underestimated, less water will be used than the optimal value and the marginal value of water will be overestimated.

In Cases 1 and 2, the reservoir operation also has a one-stage formulation. In Case 1 , the WA is sufficient to satisfy maximum demands in all periods. $\sum_{t=1}^{H} f_{t}>\sum_{t=1}^{H} q_{t}$ overestimates WA and induces spill, but the overestimation is a false increase in WA, and the induced spill can lead to water shortage in subsequent periods. By contrast, $\sum_{t=1}^{H} f_{t}<\sum_{t=1}^{H} q_{t}$ underestimates WA, and actual WA is more ample than the WA estimated by forecasts. In Case 2, a drought occurs and minimum demand is satisfied. Consider that $\sum_{t=1}^{H} f_{t}<$ $\sum_{t=1}^{H} q_{t}$ underestimates WA but does not affect water supply to meet the minimum water requirement. By contrast, $\sum_{t=1}^{H} f_{t}>$ $\sum_{t=1}^{H} q_{t}$ overestimates WA and can make the reservoir release more water than the minimum requirement, consequently, inducing water shortage in subsequent periods because the overestimation does not indicate the actual increase in WA.

In Cases 3 and 4, the reservoir operation has two stages. In Case 3, the binding constraint of the upper storage capacity at period $t_{3}$ indicates that the maximum volume of water has been carried over from stage 1 to stage $2 . r_{i}^{\prime}-r_{i}^{*}(i=$ $\left.1,2, \ldots, t_{3}\right)$ in stage 1 are not affected by forecast uncertainty in stage 2 if $\sum_{t=t_{3}+1}^{H} f_{t}<\sum_{t=t_{3}+1}^{H} q_{t}$. Therefore, water can no longer be carried over to stage 2 even though there is a forecasted drought in stage 2 . In Case 4 , the binding constraint of the lower storage capacity at period $t_{4}$ indicates the consumption of maximum available water in stage 1 . Water can no longer be carried over from stage 2 and consumed in stage 1 even though there is forecasted increase of WA in stage 2 . Therefore, $r_{i}^{\prime}-r_{i}^{*}\left(i=1,2, \ldots, t_{4}\right)$ in stage 1 are not affected by forecast uncertainty in stage 2 if $\sum_{t=t_{4}+1}^{H} f_{t}>\sum_{t=t_{4}+1}^{H} q_{t}$.

In Case 5, the reservoir operation has three stages. The binding upper (lower) storage capacity constraint blocks the effect of decreased (increased) WA in subsequent stages on release decisions in preceding stages. As a result, $r_{i}^{\prime}-r_{i}^{*}(i=$ $\left.1,2, \ldots, t ; t=\min \left(t_{3}, t_{4}\right)\right)$ in stage 1 are not affected by either $\sum_{t=T+1}^{H} f_{t}>\sum_{t=T+1}^{H} q_{t}$ or $\sum_{t=T+1}^{H} f_{t}<\sum_{t=T+1}^{H} q_{t}(T=$ $\left.\max \left(t_{3}, t_{4}\right)\right)$, suggesting that release decisions in stage 1 are irrelevant to the forecast uncertainty of streamflow in stage 3 .

The one-stage, two-stage, and three-stage formulations for the six cases indicate that the reservoir can efficiently regulate streamflow from one stage up to the period when the storage capacity constraint is binding. The effects of forecast uncertainty on $r_{i}(i=1,2, \ldots, H)$ are affected by storage capacity. Among the decisions, current decision $r_{1}$ is the most important (subsequent decisions are not final and will be determined based on updated forecasts). The one-stage formulation illustrates that in Cases 0,1 , and 2, the optimality of $r_{1}$, which is indicated by the gap between $r_{1}^{\prime}$ and $r_{1}^{*}$, is affected by the forecast uncertainty of total streamflow. The two-stage and three-stage formulations in Cases 3, 4, and 5 illustrate that the optimality of $r_{1}$ is mainly affected by the forecast uncertainty of streamflow in stage 1 because of the blocking effect of the binding storage capacity constraint.

4.2. Effect of Ending Storage. The value of ending storage, which represents water saved for periods beyond $H$, is based on some expectations of streamflow conditions beyond $H$. A larger (smaller) ending storage can be set when low-flow (high-flow) condition is expected in periods beyond $H$. Considering only the ending storage $\left(f_{t}=q_{t}, t=1,2, \ldots, H\right)$, the water balance relationship yields the following:

$$
\sum_{t=1}^{H} r_{t}^{\prime}=\mathrm{EWA}=\mathrm{WA}-\left(s_{\text {end }}^{\prime}-s_{\text {end }}\right) .
$$

In (38), a larger (smaller) $s_{\text {end }}^{\prime}$ saves more (less) water for periods beyond $H$ but results in less (more) WA in periods 1 to $H$, which should affect reservoir operation.

In Case 0, the reservoir operation has a one-stage formulation. Release decisions depend on total WA. We have (Appendix)

$$
r_{t}^{\prime}-r_{t}^{*}=-\frac{1 / b_{t}^{\prime \prime}\left(r_{t}^{*}\right)}{\sum_{i=1}^{H} 1 / b_{i}^{\prime \prime}\left(r_{i}^{*}\right)}\left(s_{\text {end }}^{\prime}-s_{\text {end }}\right), \quad(t=1, \ldots, H) .
$$

Equation (39) indicates a negative monotonic relationship between $r_{t}^{\prime}-r_{t}^{*}$ and $s_{\text {end }}^{\prime}-s_{\text {end }}$. Consider that $s_{\text {end }}^{\prime}>s_{\text {end }}$ leads to $r_{t}^{\prime}<r_{t}^{*}$ and vice versa. For special cases where $b_{t}\left(r_{t}\right)$ $(t=1,2, \ldots, H)$ is identical, we obtain the following:

$$
r_{t}^{\prime}-r_{t}^{*}=-\frac{s_{\text {end }}^{\prime}-s_{\text {end }}}{H}, \quad(t=1, \ldots, H) .
$$

As can be seen in (39) and (40), variations of ending storage are shared among release decisions in the $H$ periods. A larger variation in ending storage leads to a larger change in release decision. On the other hand, the effect of ending storage tends to reduce as $H$ increases.

In Cases 1 and 2, the one-stage formulation still characterizes reservoir operation. In Case 1, maximum demands in periods 1 to $H$ are satisfied and the marginal value of WA becomes zero. Reducing $s_{\text {end }}^{\prime}$ from $s_{\text {end }}$ results in more WA and leads to spill but does not contribute to utility. By comparison, increasing $s_{\text {end }}^{\prime}$ is favorable and saves water for periods beyond $H$. In Case 2 , a drought occurs and minimum demand is satisfied. Increasing $s_{\text {end }}^{\prime}$ from $s_{\text {end }}$ induces even less WA, whereas reducing $s_{\text {end }}^{\prime}$ increases WA in periods 1 to $H$ and can alleviate the effects of drought. 
In Cases 3 and 4, the reservoir operation has two stages. Variation in $s_{\text {end }}^{\prime}$ results in change in WA in stage 2 but does not affect WA in stage 1 . In Case 3 , increasing $s_{\text {end }}^{\prime}$ from $s_{\text {end }}$ reduces WA in stage 2 , which does not affect release decisions in stage 1 . This result can be attributed to the case where the upper storage capacity constraint is binding and the maximum WA has been carried over to stage 2. In Case 4 , reducing $s_{\text {end }}^{\prime}$ from $s_{\text {end }}$ increases WA in stage 2 but does not affect release decisions in stage 1 . This outcome can be attributed to the case where the constraint of lower storage capacity is binding and water can no longer be carried over from stage 2 to stage 1 .

In Case 5, the reservoir operation has three stages. The binding lower storage capacity constraint blocks the effects of decreased WA in stage 3 on decisions in stages 1 and 2. The binding upper storage capacity constraint blocks the effects of increased WA in stages 2 and 3 on decisions in stage 1 . Therefore, variation in $s_{\text {end }}^{\prime}$ leads to changes in WA in stage 3 but does not affect decisions in stage 1. Compared with the extensive effect of ending storage in Case 0 , the binding storage capacity constraint limits the ending storage effect.

Water is the scarce resource in reservoir operation. Increasing $s_{\text {end }}^{\prime}$ reserves more water for periods beyond $H$, whereas reducing $s_{\text {end }}^{\prime}$ allocates more water to periods 1 to $H$. When storage capacity constraints are nonbinding, the reservoir receives enough capacity to regulate streamflow in a long timeframe. Current release decision is affected by variation in $s_{\text {end }}^{\prime}$, as well as by the forecast uncertainty of total streamflow. However, with binding constraints of storage capacity, the reservoir can only regulate streamflow in a short timeframe. Ending storage may have no effect on current release decision. The findings highlight the importance of storage capacity in reservoir operation.

4.3. Implications for Reservoir Operation. The one-stage, twostage, and three-stage formulations provide information for real-time reservoir operation that confronts a long operation horizon $(\mathrm{OH})$ and a limited forecast horizon $(\mathrm{FH})$. For example, the $\mathrm{OH}$ of water supply can be one hydrological year, whereas reliable streamflow forecast has an FH of only several days in the rainy season and several weeks in the dry season $[8,34,35]$. To bridge the gap between $\mathrm{OH}$ and $\mathrm{FH}$, forecast is used to represent streamflow conditions within $\mathrm{FH}$ and ending storage is employed to indicate water saved for periods beyond $\mathrm{FH}[7,15,32]$. In this way, decision-making is subject to the joint effects of forecast uncertainty and ending storage.

Based on Monte-Carlo experiments with fixed ending storage, Zhao et al. [24, 35] analyzed the effect of forecast uncertainty on reservoir operation and found that the effect is affected by reservoir storage capacity. Improvement of forecast yields less (more) utility gain for small (large) reservoirs. By varying ending storage, Zhao et al. [9] explored the combinational effect of forecast uncertainty and ending storage on reservoir operation. The results showed that the optimality of operation decisions of small (large) reservoirs depends on forecast information within a short (long) $\mathrm{FH}$ and that it is less (more) affected by ending storage. Both studies highlighted the importance of storage capacity. Adding to the numerical findings, this study explicitly illustrates how storage capacity determines the effects of forecast uncertainty and ending storage. In reservoir operation, the current decision depends on the total WA that is affected by both forecast uncertainty and ending storage when the storage capacity has no binding constraint. For this case, improving the long-term streamflow forecast and selecting an appropriate ending storage are important. With binding constraints of storage capacity, the current decision is mainly affected by the forecast uncertainty of WA in stage 1 , and more attention should be focused on improving short-term streamflow forecast in the current stage.

\section{Conclusions}

This study presented a mathematical analysis of water supply reservoir operation and discussed the effects of three typical constraints of water balance, release capacity, and storage capacity on decision-making in detail. Water balance determines the total water availability, of which the dual value functions as a link in reservoir operation. Upper release capacity constraint hinders release increase caused by increased water availability and leads to spill, whereas lower release capacity hinders release reduction caused by decreased water availability. The effect of storage capacity constraint is more extensive than that of the release capacity constraint affecting single-period decision. The binding upper (lower) storage capacity constraint blocks the effect of decreased (increased) water availability in subsequent stages on release decisions in preceding stages. Analysis of reservoir operation constraints illustrates that multipleperiod reservoir operation can be formulated as a one-stage, two-stage, or three-stage model.

Based on the one-stage, two-stage, and three-stage formulations, we explored the effects of forecast uncertainty and ending storage on water supply decisions. In reservoir operation, forecast uncertainty indicates uncertain streamflow within forecast horizon and ending storage deals with unknown streamflow beyond the forecast horizon. The onestage formulation illustrates that, in cases without binding constraints of storage capacity, current release decision is subject to the effects of both forecast uncertainty and ending storage. In these cases, the reservoir can regulate streamflow in an extended timeframe and water supply decision is affected by streamflow conditions both within and beyond the forecast horizon. By contrast, binding constraints of storage capacity result in multiple stages in reservoir operation. The two-stage and three-stage formulations illustrate that the current release decision is mainly affected by forecast uncertainty in stage 1 because the binding storage capacity constraints block the effect of forecast uncertainty of streamflow in subsequent stages and the effect of ending storage. In these cases, the reservoir can regulate streamflow only in a short timeframe. This study explicitly addressed the effects of constraints in water supply reservoir operation and highlighted the importance of reservoir storage capacity. 


\section{Appendix}

In baseline Case 0 , no binding constraint of release and storage capacity exists. WA is the determinant of $\left[r_{1}^{*}, r_{2}^{*}, \ldots, r_{H}^{*}\right]$. Following the marginal value principle, we yield the following:

$$
\begin{gathered}
b_{1}^{\prime}\left(r_{1}^{*}\right)=\cdots=b_{H}^{\prime}\left(r_{H}^{*}\right), \\
\sum_{t=1}^{H} r_{t}^{*}=\text { WA. }
\end{gathered}
$$

Denoting $\Delta$ as variation in EWA from the actual WA and $\left[r_{1}^{\prime}, r_{2}^{\prime}, \ldots, r_{H}^{\prime}\right]$ as release decisions under EWA, based on the marginal value principle, we obtain the following:

$$
\begin{aligned}
& b_{1}^{\prime}\left(r_{1}^{\prime}\right)=\cdots=b_{H}^{\prime}\left(r_{H}^{\prime}\right), \\
& \sum_{t=1}^{H} r_{t}^{\prime}=\mathrm{EWA}=\mathrm{WA}+\Delta .
\end{aligned}
$$

Subtracting (A.1) from (A.2) yields the following:

$$
\begin{gathered}
b_{1}^{\prime}\left(r_{1}^{\prime}\right)-b_{1}^{\prime}\left(r_{1}^{*}\right)=\cdots=b_{H}^{\prime}\left(r_{H}^{\prime}\right)-b_{H}^{\prime}\left(r_{H}^{*}\right), \\
\sum_{t=1}^{H}\left(r_{t}^{\prime}-r_{t}^{*}\right)=\Delta .
\end{gathered}
$$

The Taylor expansion of $b_{t}^{\prime}\left(r_{t}\right)$ at $r_{t}=r_{t}^{*}$ yields the following:

$$
b_{t}^{\prime}\left(r_{t}^{\prime}\right)=b_{t}^{\prime}\left(r_{t}^{*}\right)+b_{t}^{\prime \prime}\left(r_{t}^{*}\right)\left(r_{t}^{\prime}-r_{t}^{*}\right) \text {. }
$$

Incorporating (A.4) into (A.3) yields the following:

$$
\begin{gathered}
b_{1}^{\prime \prime}\left(r_{1}^{*}\right)\left(r_{1}^{\prime}-r_{1}^{*}\right)=\cdots=b_{H}^{\prime \prime}\left(r_{H}^{*}\right)\left(r_{H}^{\prime}-r_{H}^{*}\right), \\
\sum_{t=1}^{H}\left(r_{t}^{\prime}-r_{t}^{*}\right)=\Delta .
\end{gathered}
$$

Solving (A.5) yields the following:

$$
r_{t}^{\prime}-r_{t}^{*}=\frac{1 / b_{t}^{\prime \prime}\left(r_{t}^{*}\right)}{\sum_{i=1}^{H} 1 / b_{i}^{\prime \prime}\left(r_{i}^{*}\right)} \Delta, \quad(t=1, \ldots, H) .
$$

\section{Conflict of Interests}

The authors declare that there is no conflict of interests regarding the publication of this paper.

\section{Acknowledgments}

The authors are grateful to the editor and the anonymous reviewers for their helpful suggestions, which have led to major improvements in this paper. This research was supported by the Ministry of Science and Technology of China (Projects nos. 2011BAC09B07 and 2013BAB05B03) and the National Natural Science Foundation of China (Projects nos. 51179085 and U1202232).

\section{References}

[1] W. W. G. Yeh, "Reservoir management and operations models: a state-of-the-art review," Water Resources Research, vol. 21, no. 12, pp. 1797-1818, 1985.

[2] R. A. Wurbs, "Reservoir system simulation and optimization models," Journal of Water Resources Planning \& Management, vol. 119, no. 4, pp. 455-472, 1993.

[3] J. W. Labadie, "Optimal operation of multireservoir systems: state-of-the-art review," Journal of Water Resources Planning and Management, vol. 130, no. 2, pp. 93-111, 2004.

[4] B. H. Dias, A. L. M. Marcato, R. C. Souza et al., "Stochastic dynamic programming applied to hydrothermal power systems operation planning based on the convex hull algorithm," Mathematical Problems in Engineering, vol. 2010, Article ID 390940, 20 pages, 2010.

[5] Y. Huang, X. Chen, Y. P. Li, A. M. Bao, and Y. G. Ma, "A simulation-based two-stage interval-stochastic programming model for water resources management in Kaidu-Konqi watershed, China," Journal of Arid Land, vol. 4, no. 4, pp. 390-398, 2012.

[6] Y. Han, Y. F. Huang, S. F. Jia, and J. H. Liu, "An intervalparameter fuzzy linear programming with stochastic vertices model for water resources management under uncertainty," Mathematical Problems in Engineering, vol. 2013, Article ID 942343, 12 pages, 2013.

[7] E. T. Alemu, R. N. Palmer, A. Polebitski, and B. Meaker, "Decision support system for optimizing reservoir operations using ensemble streamflow predictions," Journal of Water Resources Planning and Management, vol. 137, no. 1, pp. 72-82, 2010.

[8] M. A. Boucher, D. Tremblay, L. Delorme, L. Perreault, and F. Anctil, "Hydro-economic assessment of hydrological forecasting systems," Journal of Hydrology, vol. 416-417, pp. 133-144, 2012.

[9] T. Zhao, D. Yang, X. Cai, J. Zhao, and H. Wang, "Identifying effective forecast horizon for real-time reservoir operation under a limited inflow forecast," Water Resources Research, vol. 48, no. 1, 2012.

[10] F. Laufer and H. J. Morel-Seytoux, "Optimal weekly release from a seasonal reservoir. 1. Deterministic future," Water Resources Research, vol. 15, no. 2, pp. 383-398, 1979.

[11] J. R. Stedinger, B. F. Sule, and D. P. Loucks, "Stochastic dynamic programming models for reservoir operation optimization," Water Resources Research, vol. 20, no. 11, pp. 1499-1505, 1984.

[12] H. A. Loaiciga and M. A. Marino, "Risk analysis for reservoir operation," Water Resources Research, vol. 22, no. 4, pp. 483-488, 1986.

[13] T. M. Carpenter and K. P. Georgakakos, "Assessment of Folsom lake response to historical and potential future climate scenarios: 1. Forecasting," Journal of Hydrology, vol. 249, no. 1-4, pp. 148-175, 2001.

[14] H. Yao and A. Georgakakos, "Assessment of folsom lake response to historical and potential future climate scenarios 2 . Reservoir management," Journal of Hydrology, vol. 249, no. 1-4, pp. 176-196, 2001.

[15] F. X. Wang, L. Wang, H. C. Zhou, O. C. S. Valeriano, T. Koike, and W. L. Li, "Ensemble hydrological prediction-based realtime optimization of a multiobjective reservoir during flood season in a semiarid basin with global numerical weather predictions," Water Resources Research, vol. 48, no. 7, 2012.

[16] A. M. Geoffrion, "Purpose of mathematical-programming is insight, not numbers," Interfaces, vol. 7, no. 1, pp. 81-92, 1976. 
[17] A. Castelletti, S. Galelli, M. Restelli, and R. Soncini-Sessa, "Tree-based reinforcement learning for optimal water reservoir operation," Water Resources Research, vol. 46, no. 9, 2010.

[18] A. Tilmant, W. Kinzelbach, D. Juizo, L. Beevers, D. Senn, and C. Casarotto, "Economic valuation of benefits and costs associated with the coordinated development and management of the Zambezi river basin," Water Policy, vol. 14, no. 3, pp. 490-508, 2012.

[19] J. S. Shih and C. Revelle, "Water supply operations during drought: continuous hedging rule," Journal of Water Resources Planning \& Management, vol. 120, no. 5, pp. 613-629, 1994.

[20] T. R. Neelakantan and N. V. Pundarikanthan, "Hedging rule optimisation for water supply reservoirs system," Water Resources Management, vol. 13, no. 6, pp. 409-426, 1999.

[21] A. J. Draper and J. R. Lund, "Optimal hedging and carryover storage value," Journal of Water Resources Planning and Management, vol. 130, no. 1, pp. 83-87, 2004.

[22] J. Y. You and X. Cai, "Hedging rule for reservoir operations: 1. A theoretical analysis," Water Resources Research, vol. 44, no. 1, 2008.

[23] J. T. Shiau, "Analytical optimal hedging with explicit incorporation of reservoir release and carryover storage targets," Water Resources Research, vol. 47, no. 1, 2011.

[24] T. Zhao, X. Cai, and D. Yang, "Effect of streamflow forecast uncertainty on real-time reservoir operation," Advances in Water Resources, vol. 34, no. 4, pp. 495-504, 2011.

[25] M. Y. Tu, N. S. Hsu, F. T. C. Tsai, and W. W.-G. Yeh, "Optimization of hedging rules for reservoir operations," Journal of Water Resources Planning and Management, vol. 134, no. 1, pp. 3-13, 2008.

[26] N. Ilich, "Improving real-time reservoir operation based on combining demand hedging and simple storage management rules," Journal of Hydroinformatics, vol. 13, no. 3, pp. 533-544, 2011.

[27] X. Guo, T. Hu, T. Zhang, and Y. Lv, "Bilevel model for multireservoir operating policy in inter-basin water transfer-supply project," Journal of Hydrology, vol. 424-425, pp. 252-263, 2012.

[28] J. Zhao, X. Cai, and Z. Wang, "Optimality conditions for a twostage reservoir operation problem," Water Resources Research, vol. 47 , no. $8,2011$.

[29] J. F. Booker and J. C. O'Neill, "Can reservoir storage be uneconomically large?" Journal of Water Resources Planning and Management, vol. 132, no. 6, pp. 520-523, 2006.

[30] M. L. Balinski and W. J. Baumol, "The dual in nonlinear programming and its economic interpretation," Review of Economic Studies, vol. 35, no. 3, pp. 237-256, 1968.

[31] R. M. Vogel and J. R. Stedinger, "Generalized storage-reliabilityyield relationships," Journal of Hydrology, vol. 89, no. 3-4, pp. 303-327, 1987.

[32] K. P. Georgakakos and N. E. Graham, "Potential benefits of seasonal inflow prediction uncertainty for reservoir release decisions," Journal of Applied Meteorology and Climatology, vol. 47, no. 5, pp. 1297-1321, 2008.

[33] E. P. Maurer and D. P. Lettenmaier, "Potential effects of longlead hydrologic predictability on Missouri River main-stem reservoirs," Journal of Climate, vol. 17, no. 1, pp. 174-186, 2004.

[34] H. L. Cloke and F. Pappenberger, "Ensemble flood forecasting: a review," Journal of Hydrology, vol. 375, no. 3-4, pp. 613-626, 2009.

[35] T. Zhao, J. Zhao, and D. Yang, "Generalized martingale model of the uncertainty evolution of streamflow forecasts," Advances in Water Resources, vol. 57, pp. 41-51, 2013. 


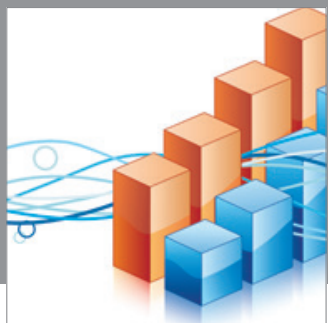

Advances in

Operations Research

mansans

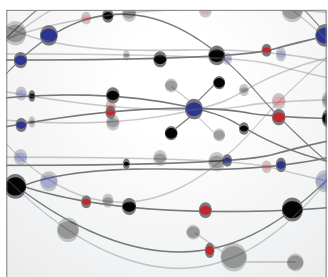

The Scientific World Journal
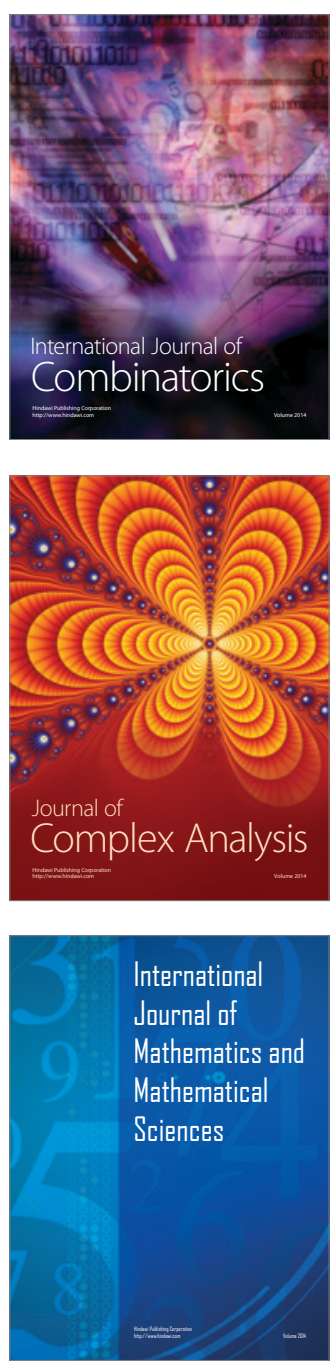
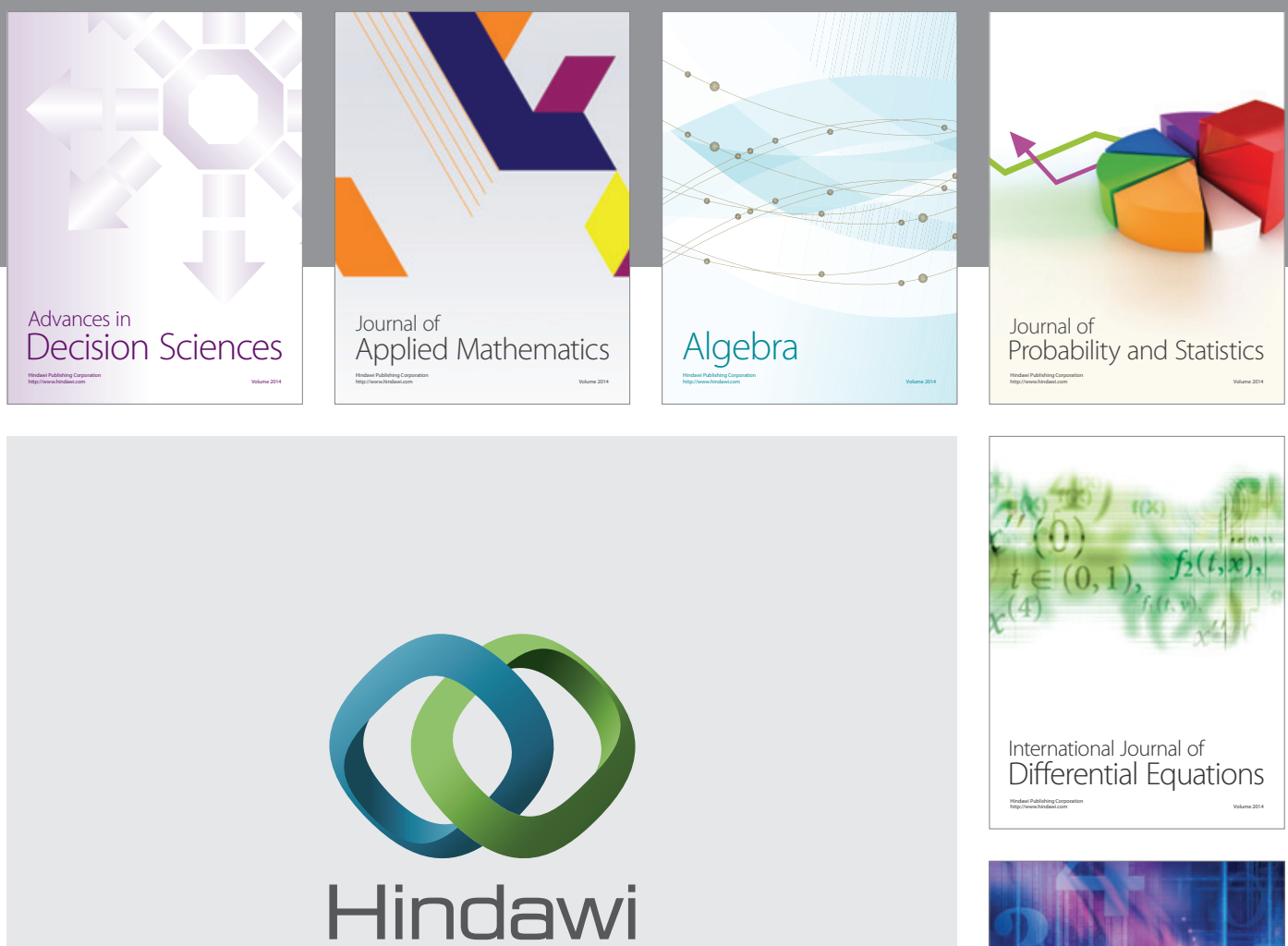

Submit your manuscripts at http://www.hindawi.com
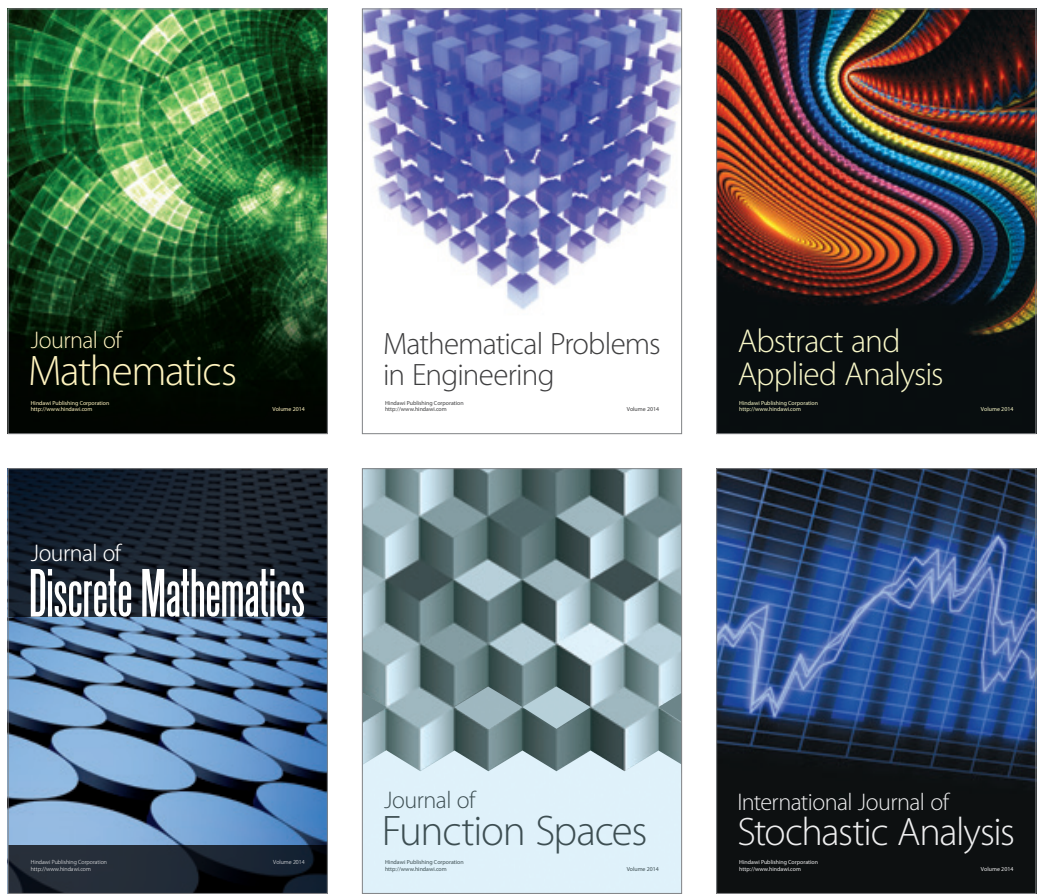

Journal of

Function Spaces

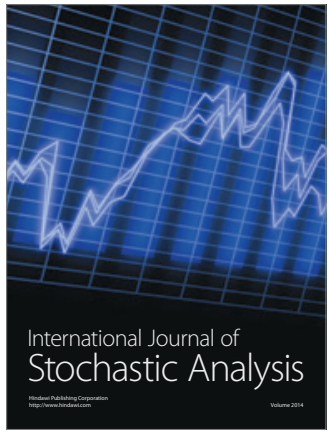

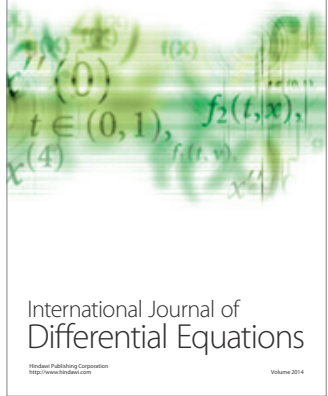
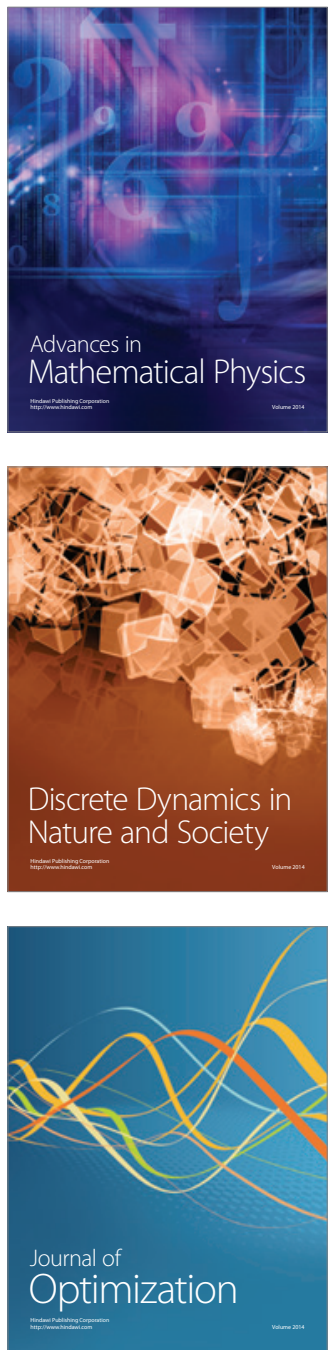